Aus der Poliklinik für Präventive Zahnmedizin, Parodontologie und Kariologie

(Prof. Dr. med. dent. A. Wiegand).

im Zentrum Zahn-Mund-Kieferheilkunde

der Medizinischen Fakultät der Universität Göttingen

\title{
Antibakterielle Wirksamkeit \\ schall- und ultraschallaktivierter \\ Wurzelkanalspülungen auf einen \\ Enterococcus faecalis-Biofilm
}

\author{
INAUGURAL-DISSERTATION \\ zur Erlangung des Doktorgrades \\ für Zahnheilkunde \\ der Medizinischen Fakultät der \\ Georg-August-Universität zu Göttingen
}

vorgelegt von

Felix Zimmermann

aus

Wiesbaden

Göttingen 2018 
Dekan:

Referentin:

Ko-Referentin:

Promotor:
Prof. Dr. rer. nat. H. K. Kroemer

Priv.-Doz. Dr. med. dent. T. Rödig

Priv.-Doz. Dr. med. dent. S. Sennhenn-Kirchner

Prof. Dr. med. Martin Oppermann

Datum der mündlichen Prüfung: 18.09.2018 
Hiermit erkläre ich, die Dissertation mit dem Titel "Antibakterielle Wirksamkeit schall- und ultraschallaktivierter Wurzelkanalspülungen auf einen intrakanalären Enterococcus faecalis-Biofilm" eigenständig angefertigt und keine anderen als die von mir angegebenen Quellen und Hilfsmittel verwendet zu haben.

Göttingen, den 



\section{Inhaltsverzeichnis}

Abbildungsverzeichnis ............................................................................... 3

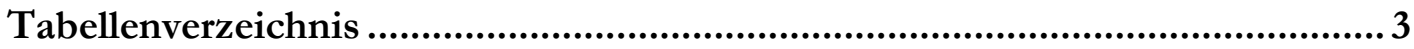

Abkürzungsverzeichnis................................................................................ 4

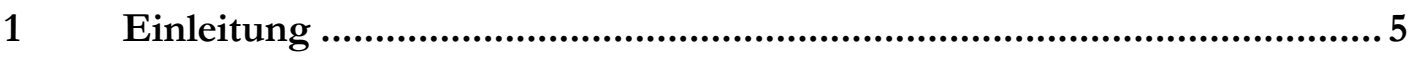

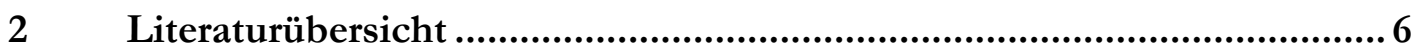

$2.1 \quad$ Die Wurzelkanalinfektion ........................................................................................ 6

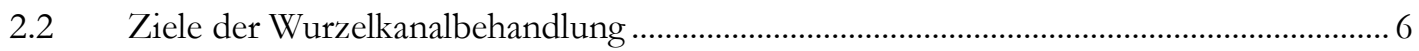

2.3 Die persistierende Wurzelkanalinfektion.......................................................................

$2.4 \quad$ Enterococcus faecalis (E. faecalis) ………………...........................................................

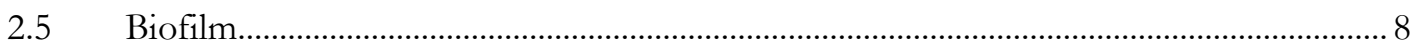

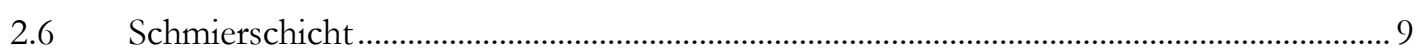

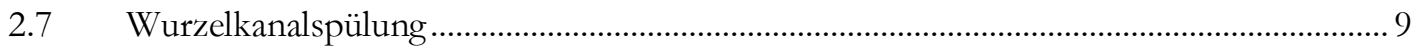

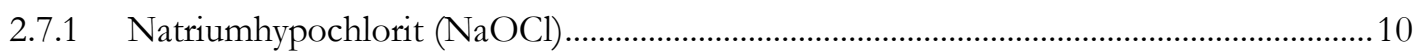

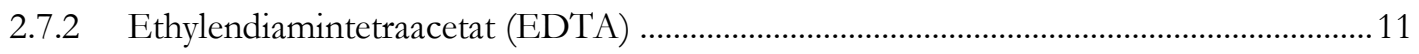

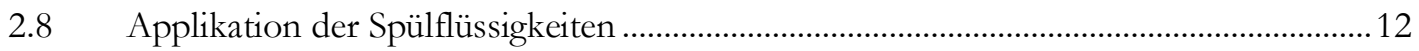

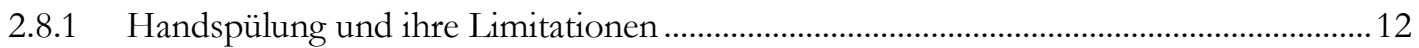

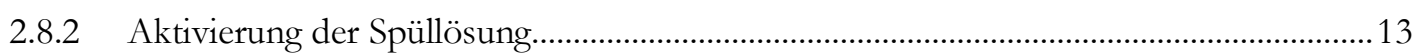

2.8.3 Erzeugung und Funktionsweise von Schall ...................................................................

2.8.4 Erzeugung und Funktionsweise von Ultraschall..........................................................14

2.8.5 Ultraschall - ,intermittent flush “(US-IF) ................................................................................15

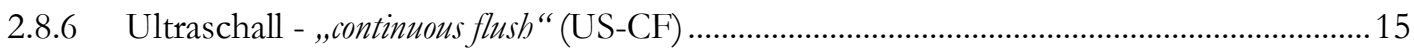

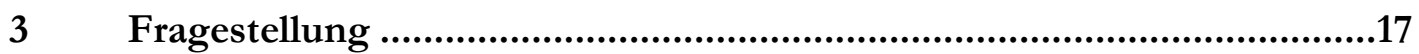

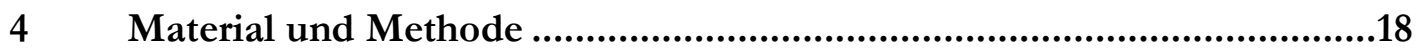

4.1 Auswahl und Vorbereitung der Zähne ...............................................................................18

4.2 Präparation und Spülung der Zähne .................................................................................19

4.3 Herstellung und Autoklavierung der Prüfkörper .................................................................2

4.4 Übersicht über den Hauptversuch..............................................................................21

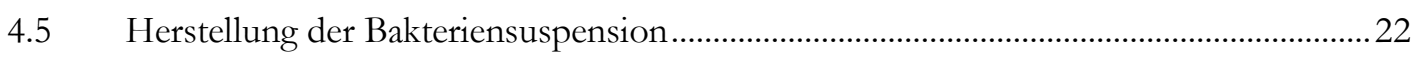

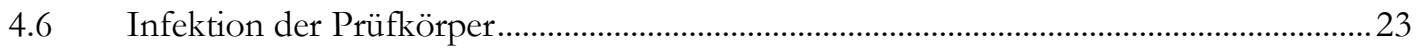

4.7 Desinfektion der Prüfkörper ......................................................................................24

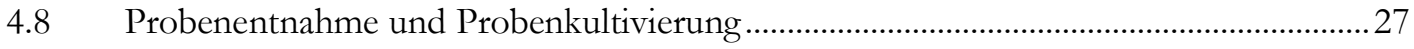

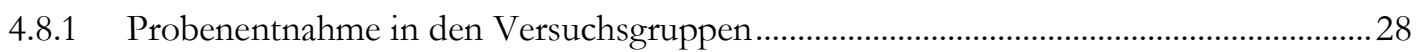

4.8.2 Probenentnahme in der Positivkontrolle..........................................................................2 


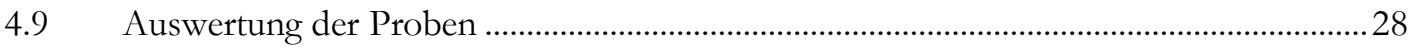

4.10 Nachweis der Schmierschichtentfernung und des Biofilms im

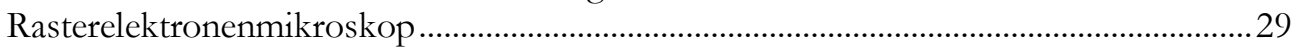

4.10.1 Vorbereitung der Zähne zum Nachweis der Schmierschichtentfernung ......................29

4.10.2 Vorbereitung der Zähne zum Nachweis des Biofilms ...................................................30

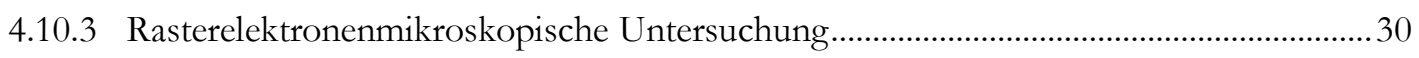

$5 \quad$ Ergebnisse......................................................................................31

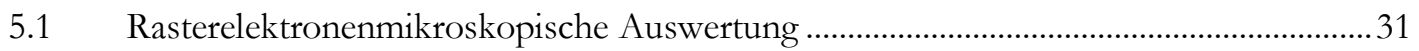

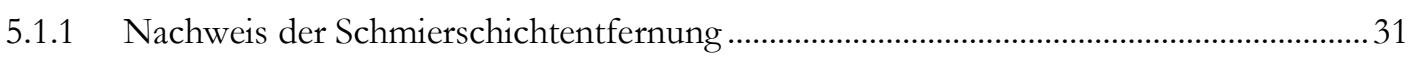

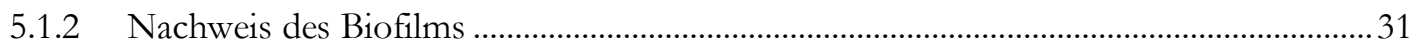

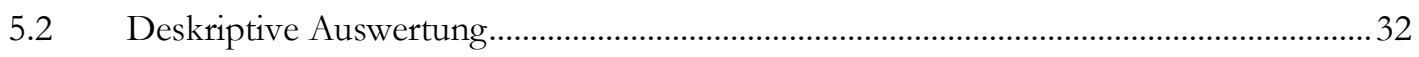

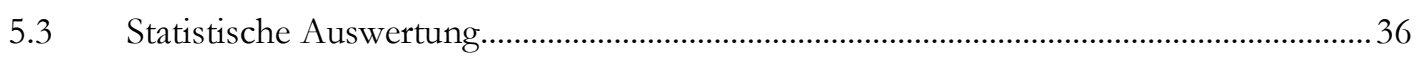

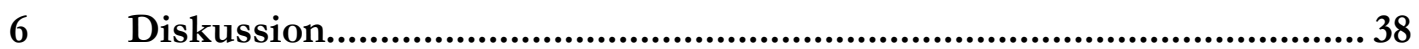

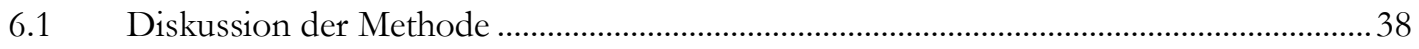

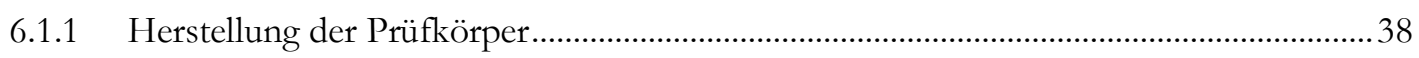

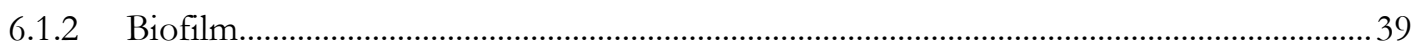

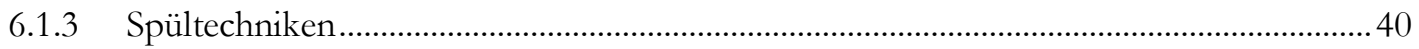

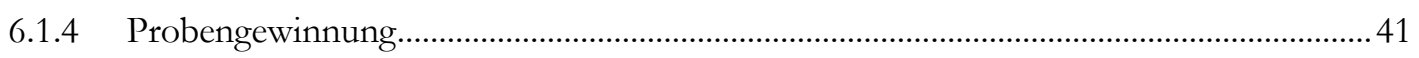

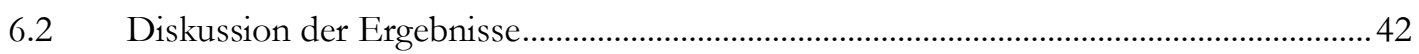

6.2.1 Vergleich der Handspülung mit schall- und ultraschallaktivierten Methoden................43

6.2.2 Vergleich von Schall- und Ultraschallaktivierung ..........................................................4 44

6.2.3 Vergleich der beiden ultraschallaktivierten Spülmethoden................................................45

7 Zusammenfassung...................................................................... 48

$8 \quad$ Literaturverzeichnis ................................................................ 50 


\section{Abbildungsverzeichnis}

Abbildung 1: In Kunststoff eingebetteter Zahn mit präpariertem Wurzelkanal........................221

Abbildung 2: Flussdiagramm über den Versuchsablauf.................................................................22

Abbildung 3: Infektion der Prüfkörper mit E. faecalis..................................................................23

Abbildung 4: Kunststoffspritze mit Spülkanüle und Gummistopper zur Längenmarkierung .. 25

Abbildung 5: EndoActivator (Dentsply) mit dem Ansatz der Größe 25/.04 ...........................26

Abbildung 6: VDW Ultra Spülgerät mit Feile der ISO-Größe 15 ..................................................26

Abbildung 7: Apparatur zur kontinuierlichen Ultraschallspülung (US-CF)...............................227

Abbildung 8: Blutagarplatte mit Bakterienkolonien...................................................................29

Abbildung 9: Mikrofotografie einer Wurzelkanaloberfläche nach Schmierschichtentfernung

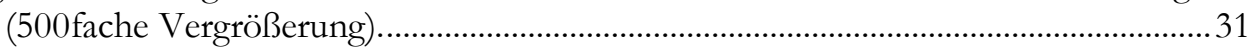

Abbildung 10: Wurzelkanaloberfläche mit E. faecalis-Biofilm (5000fache Vergrößerung)..........32

Abbildung 11: ,box plots“ der Gruppen im Vergleich........................................................................3 34

Abbildung 12: ,boxplots"der experimentellen Gruppen ohne Positivkontrolle und der Messwerte des Zahns Nummer sechs der Gruppe Schall...........................................35

\section{Tabellenverzeichnis}

Tabelle 1: Instrumentengrößen und zugehörige Arbeitslängen bei der maschinellen Präparation der Wurzelkanäle..

Tabelle 2: Übersicht über die verwendeten Spülmethoden. ......................................................24

Tabelle 3: Darstellung von Median, Mittelwert, Standardabweichung, Standardfehler und Konfidenzintervall der ausgezählten Koloniebildenden Einheiten.

Tabelle 4: Darstellung der mittleren Ränge, der Gruppengröße und der RTE der

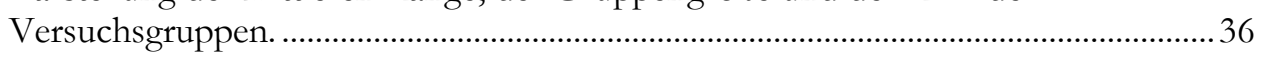

Tabelle 5: Varianzanalyse über alle Versuchsgruppen.................................................................36

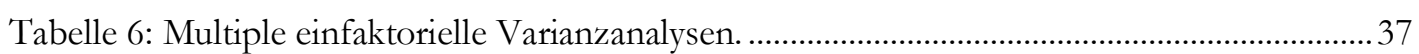




\section{Abkürzungsverzeichnis}

$\begin{array}{ll}\text { AL } & \text { Arbeitslänge } \\ \text { ANOVA } & \text { Analysis of V ariance } \\ \text { BHI } & \text { Brain Heart Infusion Broth } \\ \text { CHX } & \text { Chlorhexidin } \\ \text { CLSM } & \text { Konfokale Laser-Scanning-Mikroskopie } \\ \text { E. faecalis } & \text { Enterococcus faecalis } \\ \text { EDTA } & \text { Ethylendiamintetraacetat } \\ \text { KBE } & \text { Koloniebildende Einheiten } \\ \text { NaCl } & \text { Natriumchlorid } \\ \text { NaOCl } & \text { Natriumhypochlorit } \\ \text { REM } & \text { Rasterelektronenmikroskop } \\ \text { RTE } & \text { Relative Treatment Effects } \\ \text { US-IF } & \text { Ultraschall - Intermittent Flush } \\ \text { US-CF } & \text { Ultraschall - Continuous Flush }\end{array}$




\section{$1 \quad$ Einleitung}

Während die Infektion des Wurzelkanalsystems durch Mikroorganismen in der Vergangenheit unweigerlich zur Extraktion des betroffenen Zahnes führte, ergaben sich mit der Erfindung der Exstirpationsnadel durch Edward Maynard in der Mitte des 19. Jahrhunderts neue Therapiemöglichkeiten zur Reinigung und Desinfektion des Wurzelkanals. Da eine Wurzelkanalbehandlung häufig die einzige Alternative zur Extraktion des erkrankten Zahnes ist, hat die Endodontologie für die moderne, konservierende Zahnmedizin einen besonderen Stellenwert. Mittlerweile hat sich aus der Endodontologie eine komplexe Wissenschaft entwickelt, deren Ziel die Etablierung und Weiterentwicklung eines evidenzbasierten Behandlungskonzeptes zur Verbesserung der klinischen Erfolgsraten ist. Das Ziel der Endodontologie ist die mechanische Präparation und chemische Desinfektion des infizierten Wurzelkanalsystems sowie dessen bakteriendichter Verschluss zur Vermeidung von Reinfektionen, sodass der betroffene Zahn in Form und Funktion erhalten bleiben kann. Die erfolgreiche Therapie einer periapikalen Erkrankung funktioniert nur im Rahmen eines Gesamtkonzeptes, wobei die bestmögliche Ausführung jedes einzelnen Teilschrittes für den Erfolg der Therapie entscheidend ist. In diesem Prozess spielt die Desinfektion des Wurzelkanalsystems mit Spülflüssigkeiten eine zentrale Rolle. Obwohl wissenschaftlich erprobte Spülprotokolle zur Verfügung stehen, wird die Effektivität dieser Spülflüssigkeiten durch die komplexe Anatomie des Wurzelkanalsystems und Abwehrmechanismen der Mikroorganismen limitiert. Um die antimikrobielle Wirksamkeit der Spülflüssigkeiten zu erhöhen, werden in der modernen Endodontologie verschiedene Systeme zur Erzeugung von Schall- und Ultraschallwellen eingesetzt. Die Spülflüssigkeit im Wurzelkanal wird dadurch in Schwingungen versetzt, was zu erhöhten Strömungsgeschwindigkeiten und akustischen Strömungsphänomenen führt. Dadurch können die Desinfektionslösungen in schwer zugängliche Bereiche des Wurzelkanalsystems vordringen und den mikrobiellen Biofilm effektiver entfernen. Es ist wenig darüber bekannt, ob sich die verschiedenen Systeme zur Applikation und Aktivierung von Spülflüssigkeiten hinsichtlich ihrer antimikrobiellen Aktivität unterscheiden. In der vorliegenden In-vitroStudie wird daher die desinfizierende Wirkung verschiedener Systeme zur Schall- und Ultraschallaktivierung von Spülflüssigkeiten auf einen Enterecoccus faecalis (E. faecalis)-Biofilm untersucht. 


\section{Literaturübersicht}

\subsection{Die Wurzelkanalinfektion}

Bakterien sind der Hauptgrund für die Entstehung von Pulpitiden und apikalen Parodontitiden (Kakehashi et al. 1965; Sassone et al. 2008). In den meisten Fällen lösen kariöse Läsionen Entzündungsreaktionen innerhalb der vitalen Pulpa aus, wobei das Pulpagewebe in diesem Stadium steril ist. Bakterielle Endotoxine, die in die Pulpa gelangen, verursachen eine Hyperämie im Bereich des peripheren Kapillarplexus und einen Anstieg an phagozytierenden Zellen. Wird der bestehende Reiz (Karies) nicht entfernt, steigt die Zahl an neutrophilen Granulozyten, Lymphozyten und Makrophagen weiter an. Die durch zerfallende, phagozytierende Zellen freigesetzten Zytokine schädigen Fibroblasten und Odontoblasten im Entzündungsgebiet. Es entwickeln sich Nekrosen und Mikroabszesse in den peripheren Bereichen der Pulpa. Da das Pulpagewebe seine Abwehrfunktionen durch Sklerosierung und Reizdentinbildung nicht mehr aufrechterhalten kann, ist in diesem Stadium eine bakterielle Infektion der Pulpa möglich. Eine mikrobielle Infektion der Pulpa führt zwangsläufig zur Entstehung eines apikalen Granuloms (apikale Parodontitis) (Molven et al. 1991).

\subsection{Ziele der Wurzelkanalbehandlung}

Das Ziel der Wurzelkanalbehandlung ist die Entfernung allen vitalen und nekrotischen Gewebes sowie sämtlicher Mikroorganismen und deren Stoffwechselprodukten aus dem Endodont (Carver et al. 2007). Das Pulpagewebe sowie das bakteriell infizierte Kanalwanddentin werden dabei mit Hilfe manueller oder maschineller Instrumentierung entfernt (Schilder 1974). Vitales oder nekrotisches Pulpagewebe sowie der durch die Instrumentierung des Wurzelkanals entstandene Debris werden durch Spülung mit geeigneten Desinfektionslösungen eliminiert. Die komplexe Anatomie des Wurzelkanalsystems mit zahlreichen Isthmen, Seitenkanälen und Anastomosen verhindert häufig die vollständige Entfernung aller organischen und anorganischen Bestandteile und erschwert eine wandständige Obturation des Wurzelkanalsystems (Wu und Wesselink 2001; Peters 2004). Die zusätzliche Aktivierung der eingesetzten Spülflüssigkeit durch Schall oder Ultraschall ermöglicht eine Reinigung auch schwer zugänglicher Areale des Wurzelkanalsystems, die mit einer Handspülung nicht erreicht werden (de Gregorio et al. 2009). 


\subsection{Die persistierende Wurzelkanalinfektion}

In der Endodontie stellt die persistierende Wurzelkanalinfektion nach chemo-mechanischer Aufbereitung und Obturation des Wurzelkanalsystems eine besondere Herausforderung dar. Grund für das Fortbestehen der Infektion ist das Persistieren von Keimen innerhalb des Endodonts (Tronstad et al. 1990; Molven et al. 1991; Rôças et al. 2004a; Siqueira und Rôças 2004). Während bei der primären Infektion viele verschiedene Bakterienspezies gefunden werden (Sassone et al. 2008), sind bei persistierenden Infektionen meist wenige Bakterienspezies beteiligt (Molander et al. 1998; Sundqvist et al. 1998; Hancock et al. 2001). E. faecalis wurde mit einer Häufigkeit von 38\% (Sundqvist et al. 1998) bis 77\% (Siqueira und Rôças 2004) in Zähnen mit persistierenden Wurzelkanalinfektionen identifiziert und gilt als der am häufigsten vorkommende Keim bei endodontischen Misserfolgen (Hancock et al. 2001). In einer Übersichtsarbeit von de Paz (2007) wird allerdings die Theorie von E. faecalis als Hauptverursacher von persistierenden Wurzelkanalinfektionen hinterfragt. Das erhöhte Vorkommen von E. faecalis bei endodontischen Misserfolgen sei vielmehr auf selektive Testund Kulturmethoden zurückzuführen, die bevorzugt diese Bakterienspezies nachweisen. Invivo-Studien von Rôças et al. (2004a) und Fabricius et al. (2006) zeigten, dass E. faecalis bei persistierenden Wurzelkanalinfektionen zwar vorkommt, jedoch stets im Rahmen von Multispezies-Biofilmen. Auch Pilze wie Candida albicans und andere grampositive Bakterien wie Streptokokken und Staphylokokken wurden nach endodontischen Misserfolgen aus Zähnen isoliert (Hancock et al. 2001). Fabricius et al. (2006) fanden heraus, dass ausschließlich mit E. faecalis infizierte Zähne häufiger symptomfrei waren als Zähne, in denen mehrere Bakterienspezies identifiziert wurden.

\section{$2.4 \quad$ Enterococcus faecalis ( $E$. faecalis)}

E. faecalis ist ein nicht-sporenbildendes, grampositives, fakultativ anaerobes Kokkenbakterium und misst 0,5 $\mu \mathrm{m}$ bis $1 \mu \mathrm{m}$ im Durchmesser. Bei der frühen Besiedelung von Wurzelkanaloberflächen durch E. faecalis ist dieser in der Diplokokkenform oder kurzen Bakterienketten anzutreffen (Distel et al. 2002). Der Keim wurde nach seiner ersten Beschreibung durch Mac Collum und Hastings den Streptokokken der Gruppe D zugeordnet (Mac Collum und Hastings 1899). Seit 1984 gehört er gemeinsam mit Enterococcus faecium zur Gruppe der Enterokokken (Schleifer und Kilpper-Balz 1984). Das Bakterium kommt in der natürlichen Flora des menschlichen Darmes vor und kann über die Nahrung in den Mund und in der Folge in nekrotische oder bereits gefüllte Wurzelkanäle gelangen, wenn der betroffene Zahn nicht suffizient koronal abgedichtet ist (Zehnder und 
Guggenheim 2009). Aufgrund seiner Robustheit und der unkomplizierten Kultivierung unter aeroben sowie anaeroben Bedingungen wird E. faecalis von vielen Autoren in Studien zu endodontologischen Fragestellungen eingesetzt (Baker et al. 2004; Brito et al. 2009; Bhuva et al. 2010). E. faecalis ist in der Lage, Kohlenhydrate, Glycerin, Laktat, Malat, Zitrat, Arginin, $\alpha$-Ketosäuren und Muzine zu verstoffwechseln (Ramsey et al. 2014) und hat zahlreiche Virulenzfaktoren (Jett et al. 1994). Seine Pathogenität besteht vorwiegend in seiner Resistenz gegenüber hohen pH-Werten (Evans et al. 2002), Austrocknung, extremen Temperaturen und osmotischem Stress (Gilmore 2002; Tendolkar et al. 2003). Das Bakterium ist resistent gegen Antibiotika (Edmond et al. 1996) und toleriert lange Zeiträume ohne Nahrung (Figdor et al. 2003). Darüber hinaus ist es in der Lage, als Monokultur in gefüllten Wurzelkanälen zu überleben (Molander et al. 1998; Sundqvist et al. 1998). E. faecalis ist Natriumhypochlorit $(\mathrm{NaOCl})$ gegenüber resistenter als andere Keime (Radcliffe et al. 2004). Gering konzentriertes $(1,3 \%$ und 2,5\%) $\mathrm{NaOCl}$ eliminierte E. faecalis innerhalb von 40 min nicht, wobei 5,25\% $\mathrm{NaOCl}$ binnen 40 min eine vollständige Bakterienfreiheit erzielte (Retamozo et al. 2010). In einer anderen Studie führte 5,25\% NaOCl bereits nach $2 \mathrm{~min}$ zu vollständiger Keimfreiheit (Radcliffe et al. 2004). E. faecalis ist resistent gegenüber Kalziumhydroxid und kann durch Biofilmbildung sogar reine Kalziumhydroxid-Oberflächen besiedeln (Distel et al. 2002). E. faecalis ist in der Lage, binnen eines Tages bis zu $400 \mu \mathrm{m}$ tief in die Dentintubuli zu penetrieren (Haapasalo und Ørstavik 1987). Mit Verlängerung der Inkubationszeit stieg die Penetrationstiefe nur geringfügig an, die Anzahl der infizierten Dentintubuli nahm hingegen stark zu (Haapasalo und Ørstavik 1987). Das Bakterium kommt signifikant häufiger bei asymptomatischen und persistierenden Wurzelkanalinfektionen vor als bei symptomatischen und primären Infektionen (Hancock et al. 2001; Rôças et al. 2004b).

\subsection{Biofilm}

Ein Biofilm ist ein komplexer Verbund aus Mikroorganismen, die in eine Matrix aus bakteriellen extrazellulären Polysacchariden eingebettet sind. Biofilme bilden sich an Grenzflächen zwischen wässrigen und festen Phasen und sind in der Endodontie von großer Bedeutung (de Paz 2007). In Biofilmen organisierte Bakterien sind in diesem Verbund resistenter gegenüber Antibiotika, Desinfektionsmitteln und dem Immunsystem des Wirtes (Costerton et al. 1999; Smith und Hunter 2008) und können Schwankungen des pH-Wertes besser tolerieren als planktonisch lebende Bakterien (McNeill und Hamilton 2003). Die Resistenz gegenüber Antibiotika wird darin begründet, dass sich Bakterien in Biofilmen langsamer teilen als planktonisch lebende Bakterien (Donlan und Costerton 2002) und dass 
die gegenüber dem Antibiotikum besonders resistenten Bakterien (,persister") ihre Resistenzgene an andere Bakterien vererben (Hall-Stoodley et al. 2004). E. faecalis bildet bei längerer Inkubation (77 d) einen filamentösen, stark verzweigten, 20-30 $\mu \mathrm{m}$ dicken Biofilm mit pilzförmigen Bakterienkolonien aus (Distel et al. 2002). Innerhalb der PolysaccharidMatrix des Biofilms befinden sich Wasserkanäle, die den Austausch von Signalmolekülen zwischen den Bakterien (,quorum sensing"), den Nahrungsaustausch und den Abtransport von Stoffwechselprodukten gewährleisten (Cook et al. 1998). „Quorum sensing “ ist für die korrekte Differenzierung von bakteriellen Biofilmen essenziell (Davies 1998).

\subsection{Schmierschicht}

Bei der chemomechanischen Aufbereitung des Wurzelkanalsystems entsteht eine Schmierschicht (,,smear layer") aus Mikroorganismen, Odontoblastenfortsätzen, Pulpagewebe sowie anorganischer Zahnsubstanz (McComb und Smith 1975; Pashley 1992). Die Schmierschicht verlegt die Kanaleingänge der Dentintubuli mit den darin enthaltenen Bakterien (Mader et al. 1984; Aktener et al. 1989). Dadurch verhindert sie das Eindringen der Spülflüssigkeit in die Dentintubuli, sodass die Bakterien in diesen Bereichen von antimikrobiellen Substanzen nicht erreicht werden (Mader et al. 1984). Die Dicke der Schmierschicht beträgt je nach Untersuchung $1 \mu \mathrm{m}$ (Goldman et al. 1981), 1-2 $\mu \mathrm{m}$ (Mader et al. 1984) oder 2-5 um (Brännström und Johnson 1974). Darüber hinaus werden Anteile der Schmierschicht durch die Wurzelkanalinstrumente zwischen $40 \mu \mathrm{m}$ (Mader et al. 1984) und $100 \mu \mathrm{m}$ (Aktener et al. 1989) in die Dentintubuli hineingepresst. Die Entfernung der Schmierschicht wird empfohlen, da sie ein Eindringen der Spülflüssigkeiten in die Dentintubuli verhindert (Mader et al. 1984), Bakterien und deren Stoffwechselprodukte enthält (McComb und Smith 1975) und ein Bakterienwachstum begünstigt (Yang und Bae 2002). Cergneux et al. (1987) stellten fest, dass die Entfernung der Schmierschicht den Randspalt zwischen Kanalwanddentin und Wurzelkanalfüllung verringert. Außerdem verbessert die Entfernung der Schmierschicht die Penetration verschiedener Sealer in die Dentintubuli (White et al. 1987).

\subsection{Wurzelkanalspülung}

Die mechanische Instrumentierung der Wurzelkanäle ist oft unzureichend und große Teile der Wurzelkanalwand bleiben unbearbeitet (Wu und Wesselink 2001; Wu et al. 2003). In ovalen Wurzelkanälen finden sich auf Arbeitslänge (AL) - $3 \mathrm{~mm}$ in $65 \%$ der Fälle unbearbeitete Kanalwandabschnitte (Wu und Wesselink 2001). Rödig et al. (2002) fanden 
heraus, dass bei der Aufbereitung ovaler Wurzelkanäle mit Nickel-Titan-Instrumenten durchschnittlich 19\% des Kanalwanddentins nicht instrumentiert wurden, wobei bis zu 55\% der bukkalen und lingualen Extensionen der ovalen Kanäle unbearbeitet blieben. In einer Studie an extrahierten Oberkiefermolaren lag der Anteil an nicht instrumentierter Kanalwandoberfläche bei durchschnittlich $47 \%$ in mesio-bukkalen Kanälen, 38\% in distobukkalen Kanälen und 39\% in palatinalen Kanälen (Hübscher et al. 2003). Zudem ist das apikale Delta von Wurzelkanälen häufig stark verzweigt (Vertucci 2005). Dieses Kanalsystem kann allein durch mechanische Bearbeitung nicht ausreichend von Biofilm, Bakterien, organischem sowie anorganischem Gewebe befreit werden, da viele Bereiche nicht vom endodontischen Instrumentarium erreicht werden (Carver et al. 2007; de Gregorio et al. 2009). Aus diesen Gründen kommt den Spülflüssigkeiten in der Endodontie große Bedeutung zu. Haapasalo et al. (2010) formulierten folgende Forderungen an eine ideale Spülflüssigkeit:

- Lubrikation während der mechanischen Instrumentierung

- Herausspülen von Debris aus dem Wurzelkanal

- Penetration in nicht instrumentierte Kanalabschnitte

- Auflösung von anorganischem Gewebe (Hydroxylapatit)

- Auflösung von organischem Gewebe (Pulpagewebe und Kollagen)

- Antimikrobielle Wirkung (Elimination von Bakterien und Pilzen, Zerstörung des Biofilms)

- Entfernung der Schmierschicht (organisch/anorganisch)

- Keine Schädigung der Zahnhartsubstanzen

- Keine Irritation oder Schädigung von vitalem periapikalem Gewebe, keine zytotoxische Wirkung

Bislang existiert keine Spülflüssigkeit in der Endodontie, die all diese Forderungen gleichzeitig erfüllt (Haapasalo et al. 2010). Die am häufigsten eingesetzten Spülflüssigkeiten sind $\mathrm{NaOCl}$, Ethylendiamintetraacetat (EDTA) und Chlorhexidin (CHX) (Zehnder 2006).

\subsubsection{Natriumhypochlorit ( $\mathrm{NaOCl})$}

$\mathrm{NaOCl}$ ist die in der Endodontie am häufigsten eingesetzte Spüllösung (Gomes et al. 2000), da es effektiv vitales und nekrotisches pulpales Gewebe auflöst (Rubin et al. 1979; Wayman et al. 1979). Die Gewebe zersetzende Wirkung lässt sich durch Erhöhung der Temperatur 
nochmals steigern (Cunningham und Balekjian 1980; Moorer und Wesselink 1982). NaOCl besitzt eine starke antibakterielle Wirkung und entfernt den organischen Teil der Schmierschicht (Haapasalo et al. 2010). Es wird in wässriger Lösung in Konzentrationen von 0,5\% bis 6\% verwendet (Gomes et al. 2000; Haapasalo et al. 2010). Bei Kontakt mit Wasser reagiert $\mathrm{NaOCl}$ stark basisch:

$$
\mathrm{NaOCl}+\mathrm{H}_{2} \mathrm{O} \rightleftharpoons \mathrm{HClO}+\mathrm{OH}^{-}+\mathrm{Na}^{+}
$$

Es entsteht hypochlorige Säure ( $\mathrm{HClO})$. Diese wirkt als starkes Oxidationsmittel und entfaltet ihre antimikrobielle Wirkung durch die Oxidation von Sulfhydrylgruppen essenzieller bakterieller Enzyme, wodurch der Stoffwechsel der Bakterienzelle zum Erliegen kommt (Siqueira et al. 2000):

$$
\mathrm{HClO}+\mathrm{H}^{+}+2 \mathrm{e}^{-} \rightarrow \mathrm{Cl}^{-}+\mathrm{H}_{2} \mathrm{O}
$$

Da die Chlorid-Ionen nur schlecht wasserlöslich sind, entweichen sie bei fortbestehender Reaktion als Chlorgas $\left(\mathrm{Cl}_{2}\right)$, das für den charakteristischen Geruch von $\mathrm{NaOCl}$ verantwortlich ist. Dentinspäne reduzierten in einer In-vitro-Studie von Sirén et al. (2000) die Wirkung von $1 \% \mathrm{NaOCl}$ auf das Testbakterium E. faecalis signifikant. Harrison und Hand (1981) fanden heraus, dass die Anwesenheit organischen Materials (Hefeextrakt) die antibakterielle Effektivität von 5,25\% $\mathrm{NaOCl}$ signifikant verringerte. Dieser Effekt tritt insbesondere bei niedrig konzentrierten $\mathrm{NaOCl}$-Spülungen auf. Ein höheres Reservoir an Chlorid-Ionen kann diesen Effekten entgegenwirken. Dieses Reservoir kann entweder durch eine Erhöhung der Konzentration der Spüllösung oder durch die Vergrößerung der Menge an Spülflüssigkeit geschaffen werden. Eine Erhöhung der Konzentration des $\mathrm{NaOCl}$ führte dazu, dass geringere Kontaktzeiten nötig waren, um E. faecalis vollständig zu eliminieren (Gomes et al. 2000; Radcliffe et al. 2004). Aufgrund der Zytotoxizität von $\mathrm{NaOCl}$ (Küçükkaya 2014) liegt es jedoch nahe, die Spülflüssigkeit in möglichst niedrigen Konzentrationen einzusetzen. Häufiges Spülen mit einer erhöhten Menge an $\mathrm{NaOCl}$ kann die Verwendung niedriger konzentrierter NaOCl-Spüllösungen kompensieren (Siqueira et al. 2000). In der klinischen Praxis ist die Entscheidung, in welcher Konzentration $\mathrm{NaOCl}$ als Spülflüssigkeit eingesetzt wird, immer ein Kompromiss aus dessen Zytotoxizität und antibakterieller Wirksamkeit.

\subsubsection{Ethylendiamintetraacetat (EDTA)}

In der Endodontie wurde EDTA erstmals von Nygaard-Østby (1957) zum Erschließen stark kalzifizierter und schwer zu präparierender Wurzelkanäle erwähnt. EDTA ist ein sechszähniger Chelator und bildet stabile Komplexe mit mindestens zweiwertigen Kationen. 
Heutzutage wird es, neben Zitronensäure, in erster Linie zur Entfernung von Calcium $\left(\mathrm{Ca}^{2+}\right)$ aus den anorganischen Bestandteilen der Schmierschicht und der Hydroxylapatit-Matrix des Dentins eingesetzt (Scelza et al. 2003; Pérez-Heredia et al. 2008; Herrera et al. 2013). Zwischen 17\% EDTA und 10\% Zitronensäure bestehen keine Unterschiede in der Effektivität der Schmierschichtentfernung (Scelza et al. 2003; Pérez-Heredia et al. 2008; Herrera et al. 2013). Die antimikrobiellen und Gewebe auflösenden Eigenschaften von $\mathrm{NaOCl}$ werden durch beide Spülflüssigkeiten stark eingeschränkt (Baumgartner und Ibay 1987; Zehnder et al. 2005; Rossi-Fedele et al. 2012). Aus diesem Grund sollten EDTA und $\mathrm{NaOCl}$ nicht alternierend eingesetzt werden (Zehnder 2006). Die Präparation der Wurzelkanäle wird durch die demineralisierende Wirkung von EDTA auf das Kanalwanddentin erleichtert (Pérez-Heredia et al. 2008). Die dekalzifizierende Wirkung und die Effizienz der Schmierschichtentfernung von EDTA können durch Ultraschallaktivierung nochmals gesteigert werden (Kuah et al. 2009; Herrera et al. 2013). Eine einminütige Spülung mit 17\% EDTA führte zur vollständigen Entfernung der Schmierschicht (Calt und Serper 2002). Hülsmann et al. (2003) empfehlen in einer Übersichtsarbeit Einwirkzeiten von 1-5 min und Zehnder (2006) eine Einwirkzeit von mindestens 1 min bei einem Spülvolumen von $5 \mathrm{ml}$. In Kombination mit $\mathrm{NaOCl}$ als Abschlussspülung führte EDTA bereits nach $1 \mathrm{~min} z \mathrm{zu}$ einer effizienten Entfernung der Schmierschicht (Crumpton et al. 2005). Zehnminütige Einwirkzeiten von EDTA in Verbindung mit $\mathrm{NaOCl}$ verursach ten starke peritubuläre und intertubuläre Dentinerosionen (Calt und Serper 2002).

\subsection{Applikation der Spülflüssigkeiten}

\subsubsection{Handspülung und ihre Limitationen}

Bei der konventionellen Handspülung wird die Spülflüssigkeit mit einer Einwegspritze aus Kunststoff und einer Spülnadel aus Stahl oder Nickel-Titan in den Wurzelkanal eingebracht. Die Spitze der Spülnadel sollte bei der Wurzelkanalspülung möglichst weit nach apikal in den Wurzelkanal inseriert werden, um eine optimale Effektivität der Spülwirkung zu erreichen (Sedgley et al. 2005). Ferner sollte der Wurzelkanal mindestens auf ISO-Größe 35 präpariert werden, sodass eine Spülkanüle der Größe 30 ohne Friktion auf AL - 1 mm eingebracht werden kann (Zehnder 2006). Die Handspülung weist hinsichtlich ihrer antibakteriellen Eigenschaften und der Reinigungswirkung zahlreiche Limitationen auf. Dazu zählt der mangelhafte Austausch der Spülflüssigkeit nach Austritt aus der Kanülenspitze und die geringen Strömungsgeschwindigkeiten, wodurch die Entfernung von Biofilm und Debris aus dem Wurzelkanal erschwert wird (Boutsioukis et al. 2010; Gulabivala et al. 2010). Im 
Vergleich mit mechanisch aktivierten Spültechniken wie Schall oder Ultraschall entfernt die Handspülung weniger Debris und nekrotisches Gewebe aus schwer zugänglichen Bereichen des Wurzelkanalsystems (Burleson et al. 2007; Caron et al. 2010; Rödig et al. 2010) und hat eine eingeschränkte antibakterielle Wirksamkeit (Carver et al. 2007; Pasqualini et al. 2010).

\subsubsection{Aktivierung der Spüllösung}

Die antimikrobielle Wirksamkeit von $\mathrm{NaOCl}$ kann durch die Erhöhung des Spülvolumens (Harrison und Hand 1981), der Konzentration (Gomes et al. 2000; Radcliffe et al. 2004), der Temperatur (Gulsahi et al. 2014) und durch mechanische Aktivierung gesteigert werden (Pasqualini et al. 2010).

Bei der mechanischen Aktivierung der Spülflüssigkeit kommen verschiedene Techniken zum Einsatz. Die Spülflüssigkeit kann dabei durch manuelle Agitation mit einer Guttaperchaspitze, Systeme mit apikalem negativem Druck (EndoVac, SybronEndo, Orange, CA, USA) oder alternierenden Saug-Druck-Zyklen (RinsEndo, Dürr Dental, Bietigheim-Bissingen), sowie Schall (EndoActivator, Dentsply Sirona, York, PA, USA) oder Ultraschall appliziert und aktiviert werden. In der vorliegenden Studie wurde die konventionelle Handspülung mit insgesamt drei Schall- und Ultraschallsystemen verglichen. Die gesteigerte Reinigungswirkung von schall- und ultraschallaktivierten Spülflüssigkeiten wird zwei physikalischen Effekten zugeschrieben, nämlich akustischen Strömungsphänomenen (,acoustic streaming") und Kavitation. „Acoustic streaming" führt zu erhöhten Strömungsgeschwindigkeiten innerhalb der Spülflüssigkeit (Ahmad et al. 1987) und dadurch zu einer verbesserten Penetration der Spülflüssigkeit in schwer zugängliche Bereiche und einer effektiveren Desintegration bakterieller Biofilme (Joy et al. 2015).

Der Begriff Kavitation beschreibt die Entstehung und das Implodieren von Dampfblasen in einer schall- oder ultraschallaktivierten Flüssigkeit (Leighton 1994) und ist neben den akustischen Strömungsphänomenen für die verbesserte Reinigungswirkung der Schall- und Ultraschallsysteme verantwortlich. Kavitationseffekte von ultraschallaktivierten Feilen wurden in künstlichen Wurzelkanälen nachgewiesen (Lumley et al. 1993; Roy et al. 1994; Macedo et al. 2014), wobei der erzielte Reinigungseffekt als synergistisch mit „acoustic streaming" betrachtet wird (Ahmad et al. 1987; Ahmad et al. 1988).

\subsubsection{Erzeugung und Funktionsweise von Schall}

Zur Schallaktivierung der Spülflüssigkeit wurde in der vorliegenden Studie der EndoActivator verwendet, ein batteriebetriebenes Gerät zur mechanischen Aktivierung von 
Spülflüssigkeiten. Es stehen drei verschiedenen Polymeransätze zur Verfügung (gelb 15/.02, rot 25/.04 und blau, 35/.04). Laut Herstellerangaben soll der größtmögliche Ansatz gewählt werden, der beim Einbringen auf AL - 2 mm keine Friktion aufweist. Das Gerät kann mit drei verschiedenen Geschwindigkeitsstufen betrieben werden, die der Hersteller mit $33 \mathrm{~Hz}$, $100 \mathrm{~Hz}$ und $166 \mathrm{~Hz}$ angibt. Bei der Verwendung von Schallsystemen werden niedrigere Strömungsgeschwindigkeiten und geringere Scherkräfte entlang der Wurzelkanalwand erreicht als bei Ultraschallsystemen (van der Sluis et al. 2007). Mit der geringeren Frequenz der Schwingung geht eine erhöhte Amplitude einher, die beim EndoActivator 1,2 $\mathrm{mm}$ an der Spitze beträgt. Dadurch kommt es häufiger zu Kontakten zwischen Kanalwanddentin und Schallspitze, was Kavitationseffekte verhindert (Jiang et al. 2010).

Der EndoActivator ist der Ultraschallspülung hinsichtlich seiner antimikrobiellen Wirksamkeit und der Entfernung von Debris und nekrotischem Gewebe unterlegen (Jiang et al. 2010; Ordinola-Zapata et al. 2014), oder es fanden sich keine Unterschiede zwischen den beiden Systemen (Klyn et al. 2010). In einer Studie von Mancini et al. (2013) entfernte der EndoActivator signifikant mehr Schmierschicht als Ultraschall. Der EndoActivator entfernte Debris, Schmierschicht und Bakterien effizienter als die Handspülung (Caron et al. 2010; Pasqualini et al. 2010; Kumar et al. 2015). Andere Autoren ermittelten hinsichtlich der antimikrobiellen Wirksamkeit und der Entfernung von Debris keine Vorteile gegenüber der Handspülung (Brito et al. 2009; Li et al. 2015).

\subsubsection{Erzeugung und Funktionsweise von Ultraschall}

Ultraschallgeräte wandeln elektrische Energie in Ultraschallwellen mit Frequenzen von 25$30 \mathrm{kHz}$ um, wobei zwei verschiedene Techniken, Magnetostriktion und Piezoelektrizität, zur Erzeugung von Ultraschallschwingungen zum Einsatz kommen (van der Sluis et al. 2007). Magnetostriktion ist die hochfrequente Verformung eines ferromagnetischen Materials, beispielsweise eines Nickelstabes, in einem elektromagnetischen Feld. Piezoelektrizität beschreibt die Verformung dielektrischer Kristalle beim Anlegen einer elektrischen Spannung. Bei beiden Systemen wird die entstandene Schwingung auf eine oszillierende Feile übertragen. Wird Ultraschall dazu eingesetzt, Spülflüssigkeiten in Wurzelkanälen zu aktivieren und so deren Gewebe auflösende oder antimikrobielle Eigenschaft zu erhöhen, ohne gleichzeitig den Wurzelkanal zu präparieren, spricht man von passiver Ultraschallaktivierung.

Der Begriff passive Ultraschallaktivierung grenzt diese Methode bewusst von dem aktiven Einsatz ultraschallbetriebener Instrumente in der Endodontie ab, bei dem eine schneidende 
Wirkung der Feile auf das Dentin gewünscht ist. Derartige Instrumente werden u. a. für die Freilegung von Wurzelkanaleingängen verwendet (Martin et al. 1980; Martin und Cunningham 1984).

Innerhalb der passiven Ultraschallaktivierung der Wurzelkanalspülung haben sich wiederum zwei verschiedene Techniken etabliert: Wird nach der Handspülung die Spülflüssigkeit im Wurzelkanal in einem zweiten Schritt durch eine Ultraschallfeile aktiviert, so handelt es sich um eine intermittierende Ultraschallaktivierung (,intermittent flush “). Bei der kontinuierlichen Ultraschallaktivierung (,continuous flush“) wird durch eine ultraschallaktivierte Spülkanüle Spülflüssigkeit appliziert, sodass Spülung und Aktivierung der Spülflüssigkeit gleichzeitig stattfinden.

\subsubsection{Ultraschall - „,intermittent flush“(US-IF)}

US-IF beschreibt eine ultraschallaktivierte Feile aus Stahl oder Nickel-Titan, die im Wechsel mit der konventionellen Handspülung eingesetzt wird. Der Austausch der Spülflüssigkeit erfolgt also durch Handspülung, ihre Aktivierung erfolgt durch Ultraschall. US-IF ist der konventionellen Handspülung hinsichtlich der antimikrobiellen Wirksamkeit (Ahmad 1989; Carver et al. 2007) und der Fähigkeit, nekrotisches Gewebe und Debris aus Isthmen und apikalen Kanalabschnitten zu entfernen, überlegen (Cameron 1987; Gutarts et al. 2005; Burleson et al. 2007; Rödig et al. 2010). Außerdem kann die Spülflüssigkeit bei US-IF tiefer in die Dentintubuli eindringen als bei Schallaktivierung und Handspülung (Paragliola et al. 2010). Andere Autoren kamen allerdings zu dem Schluss, dass zwischen US-IF und Handspülung hinsichtlich der Reinigungswirkung (Mayer et al. 2002) und der antimikrobiellen Wirksamkeit (Barnett et al. 1985; Bhuva et al. 2010) keine Unterschiede bestehen.

\subsubsection{Ultraschall - „continuous flush“(US-CF)}

Bei der kontinuierlichen Ultraschallaktivierung finden Spül- und Aktivierungsvorgang simultan statt. Dabei wird eine Spülkanüle verwendet, die gleichzeitig Spülflüssigkeit fördert und im Ultraschallbereich oszilliert. Gutarts et al. (2005) zeigten in einer In-vivo-Studie an mesialen Kanälen menschlicher Molaren, dass physikalische Effekte wie „acoustic streaming“ und Kavitation auch bei ultraschallaktivierten Spülnadeln auftreten. Curtis und Sedgley (2012) und Jiang et al. (2012) führten In-vitro-Studien an geraden Wurzelkanälen durch und stellten fest, dass US-CF mehr Debris aus apikalen Kanalanteilen entfernte als die Handspülung. Adcock et al. (2011) verglichen die Effektivität der Debris-Entfernung von 
US-CF und der Handspülung aus Isthmen mesialer Wurzelkanäle unterer Molaren und konnten eine signifikant bessere Reinigungswirkung für die kontinuierliche Ultraschallaktivierung nachweisen. Gutarts et al. (2005) erzielten durch US-CF in einer Invivo-Studie an Molaren signifikant sauberere Isthmen als mit der Handspülung. In einer weiteren klinischen Studie von Burleson et al. (2007) befand sich nach chemo-mechanischer Aufbereitung der Wurzelkanäle unterer Molaren nach kontinuierlicher Ultraschallspülung signifikant weniger nekrotisches Gewebe in den apikalen Kanalanteilen und Isthmen als in den Wurzelkanälen der Gruppe Handspülung.

Kommerzielle Beispiele für Systeme zur kontinuierlichen Ultraschallaktivierung sind ProUltra PiezoFlow (Dentsply Tulsa Dental Specialities, Tulsa, OK, USA) und VPro StreamClean (Vista Dental, Racine, WI, USA). Des Weiteren wurden bereits eigens von Autoren entwickelte US-CF-Geräte in der Forschung eingesetzt (Gutarts et al. 2005; Burleson et al. 2007; Carver et al. 2007). 


\section{$3 \quad$ Fragestellung}

Das Ziel der Studie war es, die antimikrobielle Wirksamkeit der schallaktivierten sowie zweier verschiedener ultraschallaktivierter Wurzelkanalspültechniken (US-IF und US-CF) im Vergleich zur konventionellen Handspülung anhand eines E. faecalis-Biofilm-Modells zu untersuchen. 


\section{$4 \quad$ Material und Methode}

\subsection{Auswahl und Vorbereitung der Zähne}

Für die vorliegende Studie wurden einwurzelige, gerade menschliche Zähne mit einer Wurzellänge von mindestens $15 \mathrm{~mm}$ verwendet, die unmittelbar nach der Extraktion in thymolhaltigem Leitungswasser aufbewahrt wurden. Es erfolgte das Abtrennen der Zahnkronen mit Hilfe einer diamantierten Schleifmaschine (S-U Super Cut, Schuler Dental, Ulm), sodass die Wurzelkanäle eröffnet wurden. Während dieses Vorgangs wurden die Wurzelkanäle wiederholt mit Reamern der ISO-Größe 10 (VDW, München) sondiert und dabei auf Gängigkeit, Länge und akzessorische Kanäle überprüft. Der Reamer wurde dabei so tief in den Wurzelkanal inseriert, bis die Instrumentenspitze am apikalen Foramen zu erkennen war. In dieser Position wurde die Arbeitslänge mit einem Gummistopper am Instrumentenschaft markiert. Als Referenzpunkt diente die plangeschliffene Fläche des koronalen Wurzelabschnitts. Das apikale Foramen wurde zudem unter Zuhilfenahme einer Lupenbrille auf seine Unversehrtheit überprüft.

Der Reamer wurde aus dem Wurzelkanal entfernt und die Länge des Instruments mit einer Minifix-Messlehre (VDW) bestimmt. Zähne mit einer Wurzellänge unter $15 \mathrm{~mm}$ wurden direkt verworfen. Zähne mit einer Wurzellänge über $15 \mathrm{~mm}$ wurden weiter von koronal gekürzt, bis eine Länge von 15 mm erreicht war. Bei Vorliegen akzessorischer Wurzelkanäle oder Isthmen sowie bei Obliterationen des Wurzelkanals wurde der Zahn aussortiert. Ein nicht abgeschlossenes Wurzelwachstum sowie vorherige endodontische Behandlungen waren ebenfalls Ausschlusskriterien. Mit einem Reamer der ISO-Größe 20 wurde der Durchmesser des apikalen Foramens überprüft und Zähne mit einem größeren Foramen als 0,2 $\mathrm{mm}$ aus der Untersuchung ausgeschlossen. Die auf diese Weise vorbereiteten Proben wurden erneut in thymolhaltigem Leitungswasser aufbewahrt.

Im Anschluss wurden die Zähne mit Hilfe eines Ultraschallscalers von Konkrementen sowie von äußeren Verunreinigungen befreit. Unter Wasserkühlung wurden mit einem 2,5 mm breiten diamantierten Präparationszylinder (Meisinger, Neuss) standardisierte Vertiefungen von $3 \mathrm{~mm}$ Länge präpariert, die der Simulation des Pulpenkavums und als Reservoir für die Spülflüssigkeit dienten. 


\subsection{Präparation und Spülung der Zähne}

Um standardisierte Wurzelkanäle mit möglichst gleichen Volumina und Konizitäten zu erhalten, erfolgte die maschinelle Präparation mit FlexMaster Nickel-Titan-Instrumenten (VDW) von koronal nach apikal (,crown-down“-Technik) bis zur Größe 40/.02. Bei der maschinellen Aufbereitung wurde für jeden Arbeitsschritt die vom Hersteller vorgegebene Sequenz mit den entsprechenden Umdrehungs- und Drehmomentwerten am Endo-Motor (Endo IT professional, Aseptico Inc., Woodinville, WA, USA) eingestellt. Die Arbeitslänge wurde auf $14 \mathrm{~mm}$ festgelegt. Die Präparationssequenzen und deren Reihenfolge sind in Tabelle 1 zusammengefasst.

Tabelle 1: Instrumentengrößen und zugehörige Arbeitslängen bei der maschinellen Präparation der Wurzelkanäle. $\mathrm{FM}=$ FlexMaster, $\mathrm{AL}=$ Arbeitslänge

\begin{tabular}{ll}
\hline Instrument & Eindringtiefe \\
\hline FM $30 / .06$ & AL - $6 \mathrm{~mm}$ \\
\hline FM $25 / .06$ & AL - $4 \mathrm{~mm}$ \\
\hline FM $20 / .06$ & AL - $2 \mathrm{~mm}$ \\
\hline FM $30 / .04$ & AL \\
\hline FM $35 / .02$ & AL \\
\hline FM $40 / .02$ & AL \\
\hline
\end{tabular}

Vor Beginn der Präparation wurde der Wurzelkanal mit 1\% NaOCl aufgefüllt. Zum Spülen während der Präparation der Zähne wurden 5-ml-Discardit-II-Kunststoffspritzen (Becton Dickinson, Fraga, Spanien) mit Spülkanülen mit einem Außendurchmesser von 0,3 mm (Endo-EZE, Ultradent Products, South Jordan, UT, USA) verwendet. Die Arbeitslänge der jeweiligen Feile wurde mit Hilfe eines Gummistoppers markiert.

Nach jedem Instrumentenwechsel erfolgte eine Spülung des Wurzelkanals mit $2 \mathrm{ml}$ 1\% $\mathrm{NaOCl}$. Nach Applikation von $1 \mathrm{ml} \mathrm{NaOCl}$ wurde mit einem Reamer der ISO-Größe 10 die Arbeitslänge rekapituliert, um eine Verblockung der apikalen Konstriktion des Wurzelkanals durch Dentinspäne zu verhindern. Anschließend wurde der Spülvorgang fortgesetzt. Als Abschlussspülung dienten $5 \mathrm{ml}$ 19\% EDTA (Calcinase, Lege Artis, Dettenhausen), gefolgt 
von $5 \mathrm{ml} \mathrm{1 \%} \mathrm{NaOCl}$. Die Spüldauer betrug jeweils 2 min. Anschließend wurden die Zähne für 2 min in ein Ultraschallbad mit 19\% EDTA gelegt, um die präparationsbedingte Schmierschicht zu entfernen. Zehn Zähne wurden randomisiert ausgewählt und für die spätere Verwendung zur Kontrolle im Rasterelektronenmikroskop (REM) separat aufbewahrt.

\subsection{Herstellung und Autoklavierung der Prüfkörper}

Vor dem Einbetten der Zähne in Paladur wurde der Apikalbereich mit einem fließfähigen Komposit (Venus Flow, Heraeus, Hanau) versiegelt. Um auszuschließen, dass eventuell vorhandenes Restmonomer eine bakterizide Wirkung hat, wurden in einem Vorversuch zwei Reagenzgläschen vorbereitet, die beide eine Bakteriensuspension mit gleich hoher Bakteriendichte enthielten. Die Bakteriendichte wurde zuvor spektrophotometrisch bestimmt (siehe 4.5 Herstellung der Bakteriensuspension). In eines der beiden Reagenzgläschen wurde ein Streifen lichtgehärtetes Komposit gegeben. Beide Gläschen wurden zur Inkubation bei $37^{\circ} \mathrm{C}$ für $72 \mathrm{~h}$ in den Brutschrank (Thermo Scientific, Heraeus) gestellt. Nach dieser Zeit wurden die Extinktionen der beiden Bakteriensuspensionen erneut gemessen. In beiden Reagenzgläschen hatte ein exponentielles Bakterienwachstum stattgefunden und es bestanden keine Unterschiede zwischen den Extinktionswerten der Probe mit Komposit und der Probe ohne Komposit. Nach der Versiegelung der Wurzelspitzen mit fließfähigem Komposit erfolgte das Einbetten der Zähne in chemisch härtenden Kunststoff (Paladur, Heraeus). Anschließend wurden die Prüfkörper für 20 min bei $121{ }^{\circ} \mathrm{C}$ autoklaviert. Abbildung 1 zeigt einen fertiggestellen Prüfkörper. 


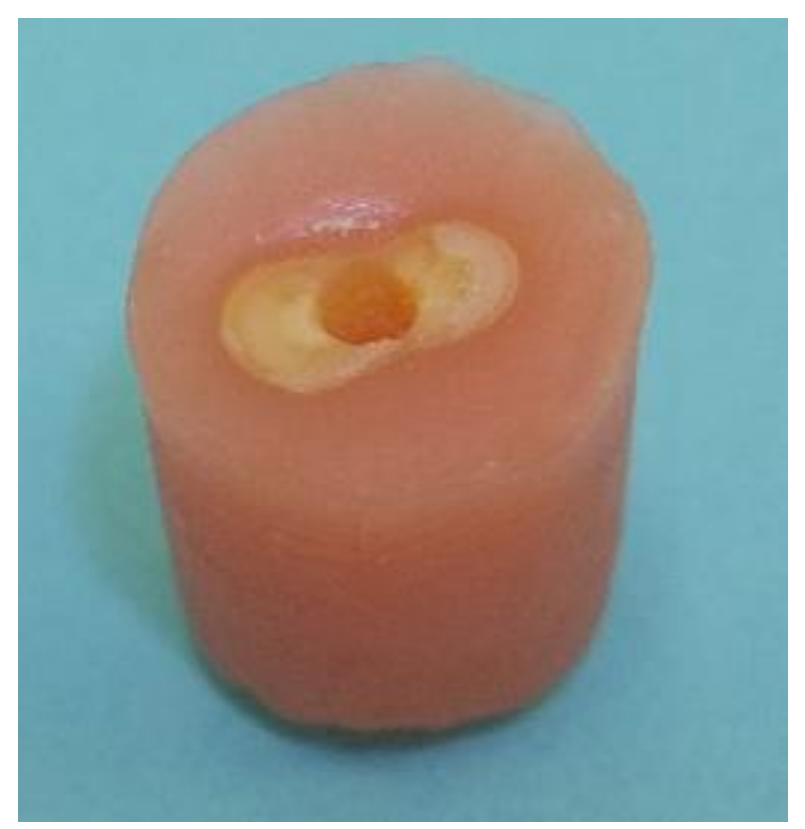

Abbildung 1: In Kunststoff eingebetteter Zahn mit präpariertem Wurzelkanal

\section{4 Übersicht über den Hauptversuch}

Für die vorliegende Studie wurden insgesamt 70 Prüfkörper hergestellt. Sechzig Prüfkörper wurden randomisiert in vier experimentelle Gruppen sowie eine Negativ- und eine Positivkontrollgruppe aufgeteilt $(n=10)$. Die verbleibenden zehn Prüfkörper wurden in zwei Gruppen zum Nachweis der Schmierschichtentfernung und zum Nachweis des E. faecalisBiofilms im REM aufgeteilt $(n=5)$. Abbildung 2 gibt einen Überblick über den Versuchsablauf. 


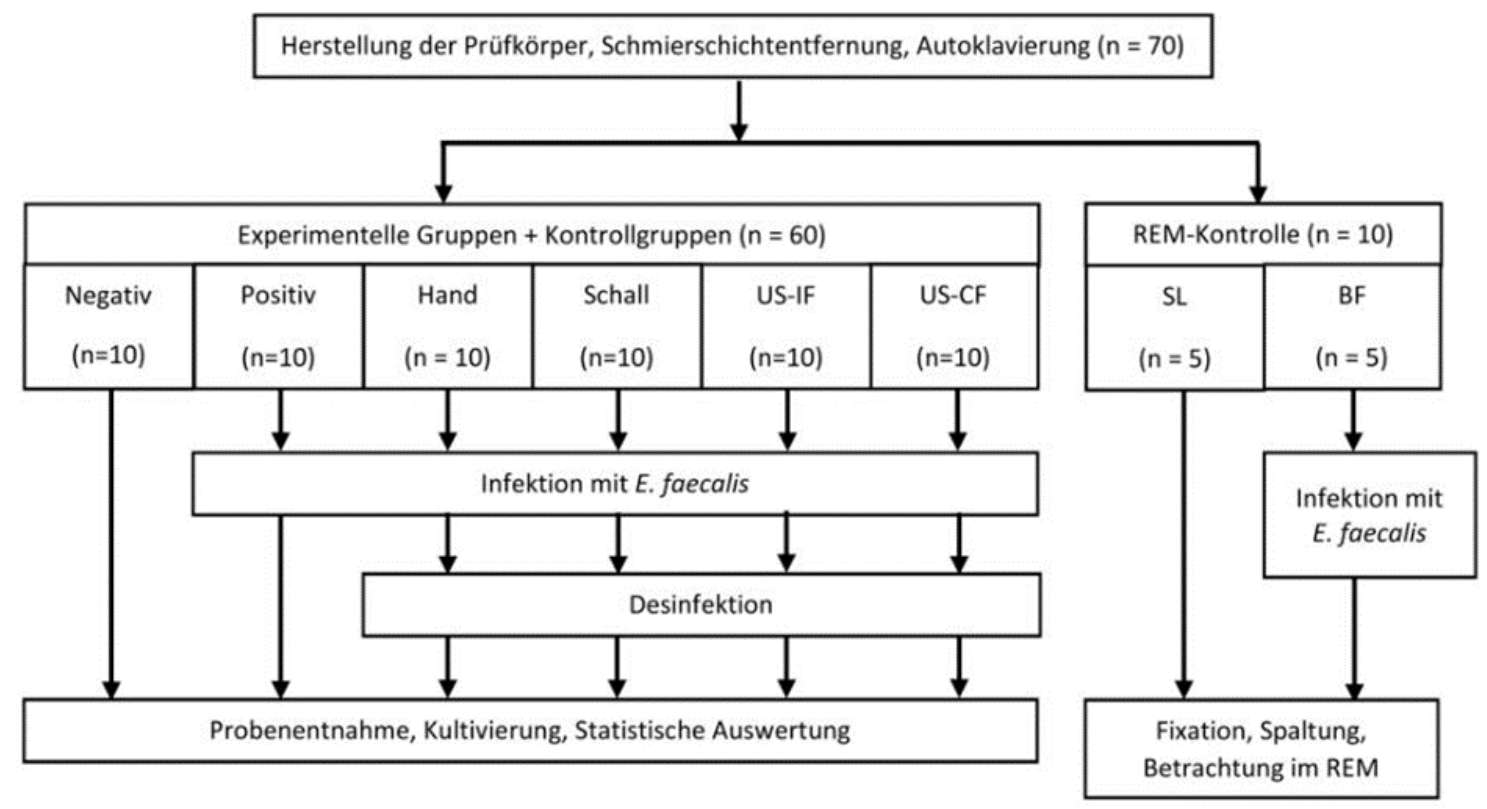

Abbildung 2: Flussdiagramm über den Versuchsablauf. Negativ $=$ Negativkontrolle, Positiv $=$ Positivkontrolle, Hand $=$ Handspülung, Schall $=$ Schallaktivierung, US-IF $=$ Intermittierende Ultraschallaktivierung, US-CF = Kontinuierliche Ultraschallaktivierung, $\mathrm{SL}=$ Schmierschicht, BF = Biofilm, REM = Rasterelektronenmikroskop

\subsection{Herstellung der Bakteriensuspension}

Zur Herstellung der Bakteriensuspension wurde ein 10-ml-Röhrchen „brain heart infusion

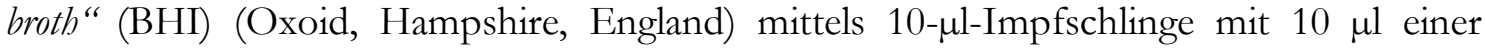
Reinkultur von E. faecalis (Stamm ATCC 29212) inokuliert. Die so entstandene Kultur wurde für $24 \mathrm{~h}$ bei $37^{\circ} \mathrm{C}$ im Brutschrank inkubiert. Um die Reinheit der Kultur zu überprüfen, wurden $10 \mu$ Flüssigkeit mit einer Impfschlinge auf je einer Blutagarplatte (Columbia Blutagar, Biomérieux, Craponne, Frankreich) ausgestrichen, diese danach für 24 h bei $37^{\circ} \mathrm{C}$ in einem Brutschrank inkubiert und anschließend visuell auf Homogenität der Bakterienkolonien überprüft.

Nach 24 h Inkubation erfolgte die Verdünnung die Bakteriensuspension auf eine reproduzierbare Bakteriendichte. Mit einem Spektrophotometer (BioPhotometer plus, Eppendorf, Hamburg) wurde zunächst bei $600 \mathrm{~nm}$ Wellenlänge die Ausgangsextinktion der

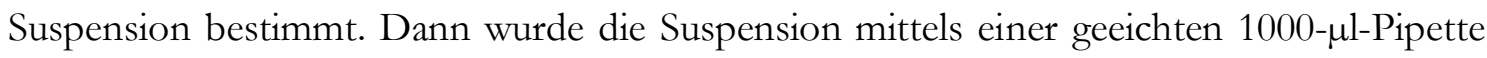
(Eppendorf) sukzessive mit reiner BHI verdünnt, bis der gewünschte Extinktionswert von 0,3 bei $600 \mathrm{~nm}$ Wellenlänge erreicht war. Dieser Wert entspricht einer Bakteriendichte von $1,5 \times 10^{8}$ Bakterien pro $\mathrm{ml}$ oder aber einem McFarland Standard von 0,5 bei einer homogenen Escherichia coli-Suspension (Hockett et al. 2008). Alle Proben wurden mit einer 
500- $\mu$ l-Pipette aus der Mitte des Becherglases entnommen. Die Extinktionsmessungen fanden in 500- $\mu$ l-Kunststoffküvetten (Sarstedt, Nümbrecht) statt. Der Rührmechanismus wurde während der Probenentnahme nicht unterbrochen, um möglichst homogene Proben zu gewinnen. Nach Abschluss der Verdünnung wurden $2 \mathrm{ml}$ der Bakteriensuspension mit einer sterilen Kunststoffspritze aus der Mitte des Becherglases aufgenommen.

\subsection{Infektion der Prüfkörper}

Vor dem Beimpfen der 65 Prüfkörper erfolgte deren randomisierte Aufteilung in acht Gruppen. Die Prüfkörper der experimentellen Gruppen, die Positivproben und die Proben für den Nachweis des Biofilms im REM wurden mit einer 2-ml-Spritze sowie einer EndoEZE-Spülkanüle der Größe 30 mit der Bakteriensuspension beimpft. Die nach Gruppen beschrifteten und mit dem Tagesdatum versehenen Schalen wurden daraufhin zur aeroben Inkubation bei $37^{\circ} \mathrm{C}$ für $72 \mathrm{~h}$ in den Brutschrank gestellt. Abbildung 3 zeigt die Beimpfung der Prüfkörper.

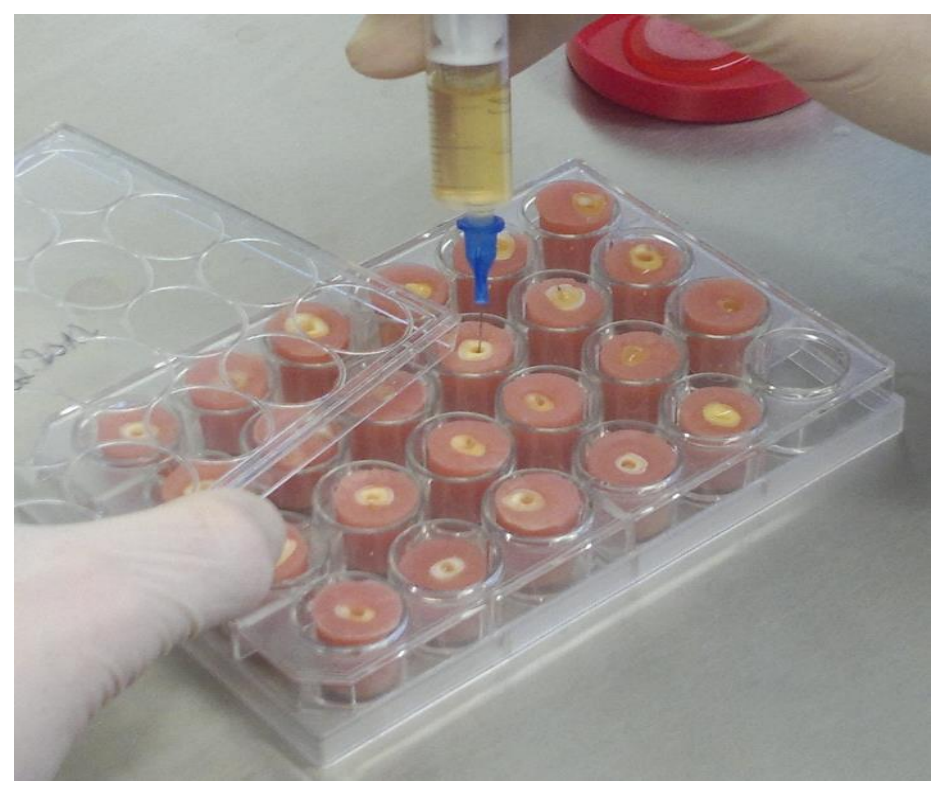

Abbildung 3: Infektion der Prüfkörper mit E. faecalis

Nach 24 h und 48 h wurde frische Bakteriensuspension hergestellt und eine Nachimpfung der Proben nach dem gleichen Protokoll durchgeführt. Die Negativproben wurden mit steriler Nährlösung gefüllt und ebenfalls für $72 \mathrm{~h}$ aerob im Brutschrank inkubiert. 


\subsection{Desinfektion der Prüfkörper}

Nach der Inkubation der Prüfkörper im Brutschrank erfolgte die Desinfektion der Wurzelkanäle in den vier experimentellen Gruppen nach dem in Tabelle 2 dargestellten Spülprotokoll. Die Desinfektion fand in allen Gruppen mit jeweils $6 \mathrm{ml} 1 \% \mathrm{NaOCl}$ statt, welches mit 5-ml-Spritzen appliziert wurde.

Tabelle 2: Übersicht über die verwendeten Spülmethoden. $\mathrm{AL}=$ Arbeitslänge, Positiv $=$ Positivkontrolle, Hand $=$ Handspülung, Schall $=$ Schallaktivierung, US-IF $=$ Intermittierende Ultraschallaktivierung, US-CF $=$ Kontinuierliche Ultraschallaktivierung, $\mathrm{NaOCl}=$ Natriumhypochlorit, $\mathrm{NaCl}=$ Kochsalzlösung

\begin{tabular}{|c|c|c|c|c|c|}
\hline $\begin{array}{c}\text { Versuchs- } \\
\text { gruppe }\end{array}$ & Positiv & Hand & Schall & US-IF & US-CF \\
\hline Eindringtiefe & $\mathrm{AL}-1 \mathrm{~mm}$ & $\mathrm{AL}-1 \mathrm{~mm}$ & $\mathrm{AL}-2 \mathrm{~mm}$ & $\mathrm{AL}-1 \mathrm{~mm}$ & $\mathrm{AL}-1 \mathrm{~mm}$ \\
\hline \multirow{4}{*}{ Zyklus } & $3 \times 30 s$ & $3 \times 30 s$ & $3 \times 30 s$ & $3 \times 30 s$ & $3 \times 30 s$ \\
\hline & spülen & spülen & spülen & spülen & spülen \\
\hline & $3 \times 30 s$ & $3 \times 30 s$ & $3 \times 30 s$ & $3 \times 30 s$ & $3 \times 30 s$ \\
\hline & einwirken & einwirken & aktivieren & aktivieren & aktivieren \\
\hline \multirow{2}{*}{ Spüllösung } & $6 \mathrm{ml}$ & $6 \mathrm{ml}$ & $6 \mathrm{ml}$ & $6 \mathrm{ml}$ & $6 \mathrm{ml}$ \\
\hline & $0,9 \% \mathrm{NaCl}$ & $1 \% \mathrm{NaOCl}$ & $1 \% \mathrm{NaOCl}$ & $1 \% \mathrm{NaOCl}$ & $1 \% \mathrm{NaOCl}$ \\
\hline \multirow{2}{*}{$\begin{array}{l}\text { Abschluss- } \\
\text { spülung }\end{array}$} & $3 \mathrm{ml}$ & $3 \mathrm{ml}$ & $3 \mathrm{ml}$ & $3 \mathrm{ml}$ & $3 \mathrm{ml}$ \\
\hline & $0,9 \% \mathrm{NaCl}$ & $0,9 \% \mathrm{NaCl}$ & $0,9 \% \mathrm{NaCl}$ & $0,9 \% \mathrm{NaCl}$ & $0,9 \% \quad \mathrm{NaCl}$ \\
\hline
\end{tabular}

Als Spülkanüle wurde eine Endo-EZE-Kanüle der Größe 30 verwendet, mit deren Hilfe 2 $\mathrm{ml} \mathrm{NaOCl}$ in $30 \mathrm{~s}$ appliziert wurden (Abbildung 4). 


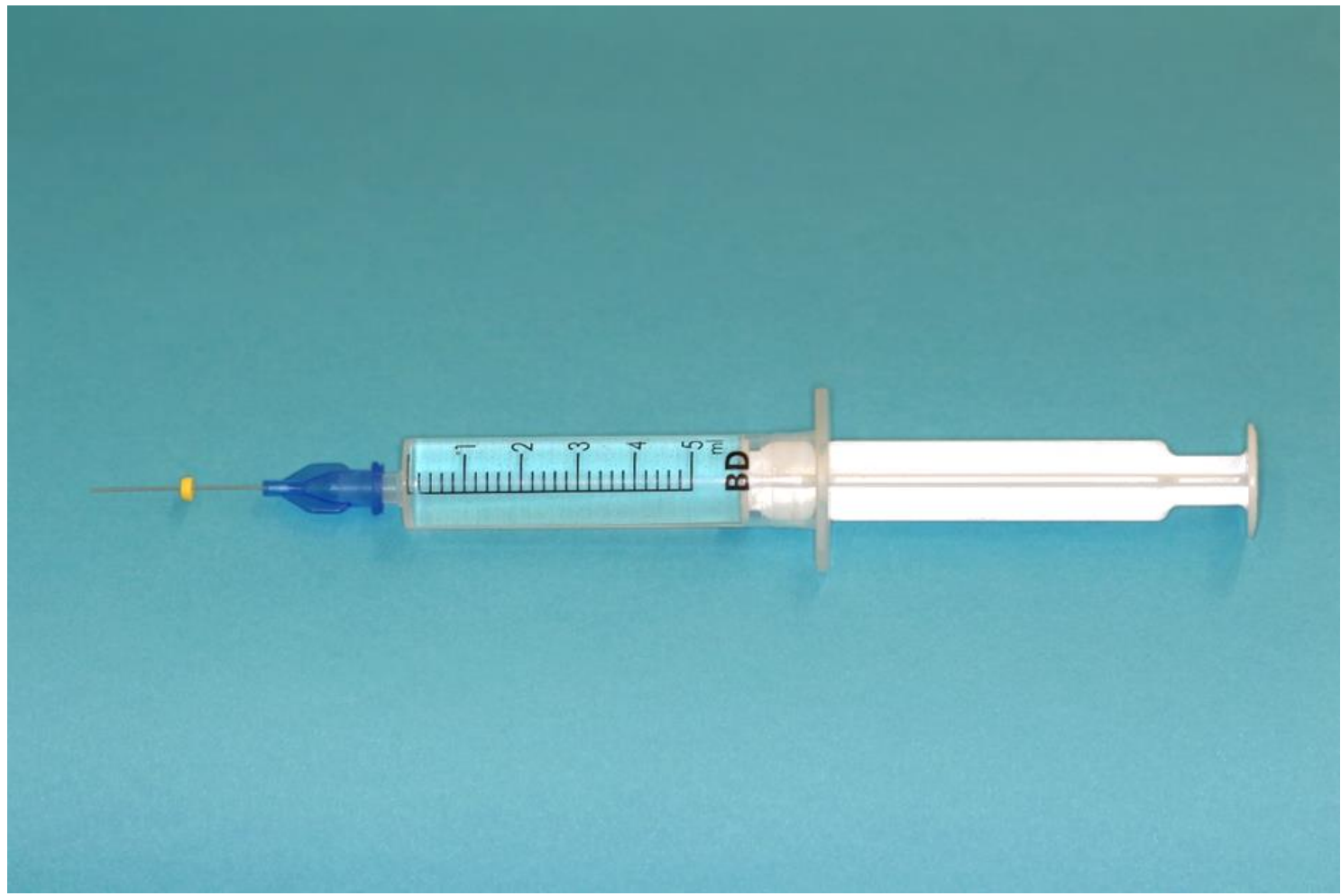

Abbildung 4: Kunststoffspritze mit Spülkanüle und Gummistopper zur Längenmarkierung

Die Spülkanüle wurde hierzu mittels Gummistopper markiert und auf AL - $1 \mathrm{~mm}$ in den Wurzelkanal eingebracht. In den verschiedenen experimentellen Gruppen wirkte die Spülflüssigkeit entweder $30 \mathrm{~s}$ ein oder wurde für $30 \mathrm{~s}$ aktiviert (Tabelle 2). Nach drei dieser Zyklen war die Desinfektion nach einer standardisierten Dauer von 3 min abgeschlossen und die Wirkung des $\mathrm{NaOCl}$ wurde durch eine Spülung mit $3 \mathrm{ml}$ isotonischer Kochsalzlösung $(0,9 \% \mathrm{NaCl})$ (B. Braun, Melsungen) unterbrochen.

Die Spülung der Prüfkörper der Positivkontrolle erfolgte wie in der Gruppe Handspülung mit insgesamt $9 \mathrm{ml} \mathrm{NaCl}$ mit einer $5 \mathrm{ml}$ Spritze und einer Endo-EZE-Kanüle der Größe 30. Bei der Handspülung und der Positivkontrolle fand zwischen den drei oben beschriebenen Spülintervallen keine mechanische Aktivierung der Spülflüssigkeit statt.

Für die Schallaktivierung der Spülflüssigkeit wurde der EndoActivator (Dentsply Tulsa Dental Specialities, Tulsa, OK, USA) mit einem Ansatz der Größe medium/rot versehen (Abbildung 5). Dieser Ansatz der Größe 25/.04 weist eine Arbeitslänge von 22 mm auf. Er wurde entsprechend der Herstellerempfehlungen ausgewählt. Dabei soll der größtmögliche Ansatz, der bei Insertion in den Wurzelkanal auf AL - $2 \mathrm{~mm}$ keine Friktion aufweist, verwendet werden. Von drei verfügbaren Intensitäten wurde die höchste Leistungseinstellung mit einer Frequenz von $166 \mathrm{~Hz}$ ausgewählt und für 3 x 30 s aktiviert. 


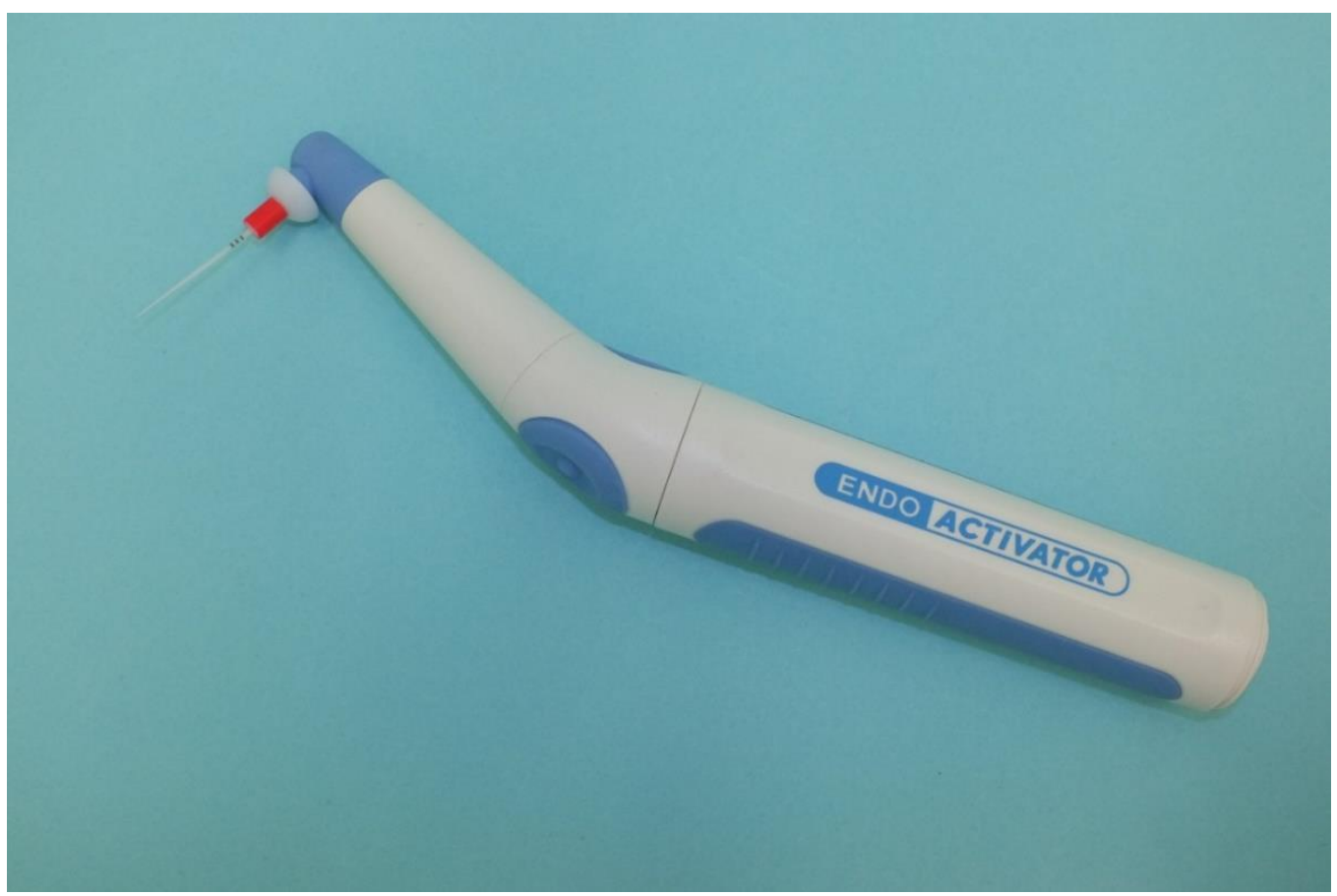

Abbildung 5: EndoActivator (Dentsply) mit dem Ansatz der Größe 25/.04

Für die Aktivierung der Spülflüssigkeit mittels US-IF wurde ein VDW Ultra Ultraschallgerät mit einer Feile der ISO-Größe 15 (VDW) verwendet (Abbildung 6). Am Gerät wurde die höchste Intensität innerhalb der für die Wurzelkanalspülung vorgesehenen Skala eingestellt (25\%). Die Feile wurde auf AL - $1 \mathrm{~mm}$ in den Wurzelkanal inseriert und für 3 x $30 \mathrm{~s}$ aktiviert. Anschließend wurde die Spülflüssigkeit durch Handspülung ausgetauscht.

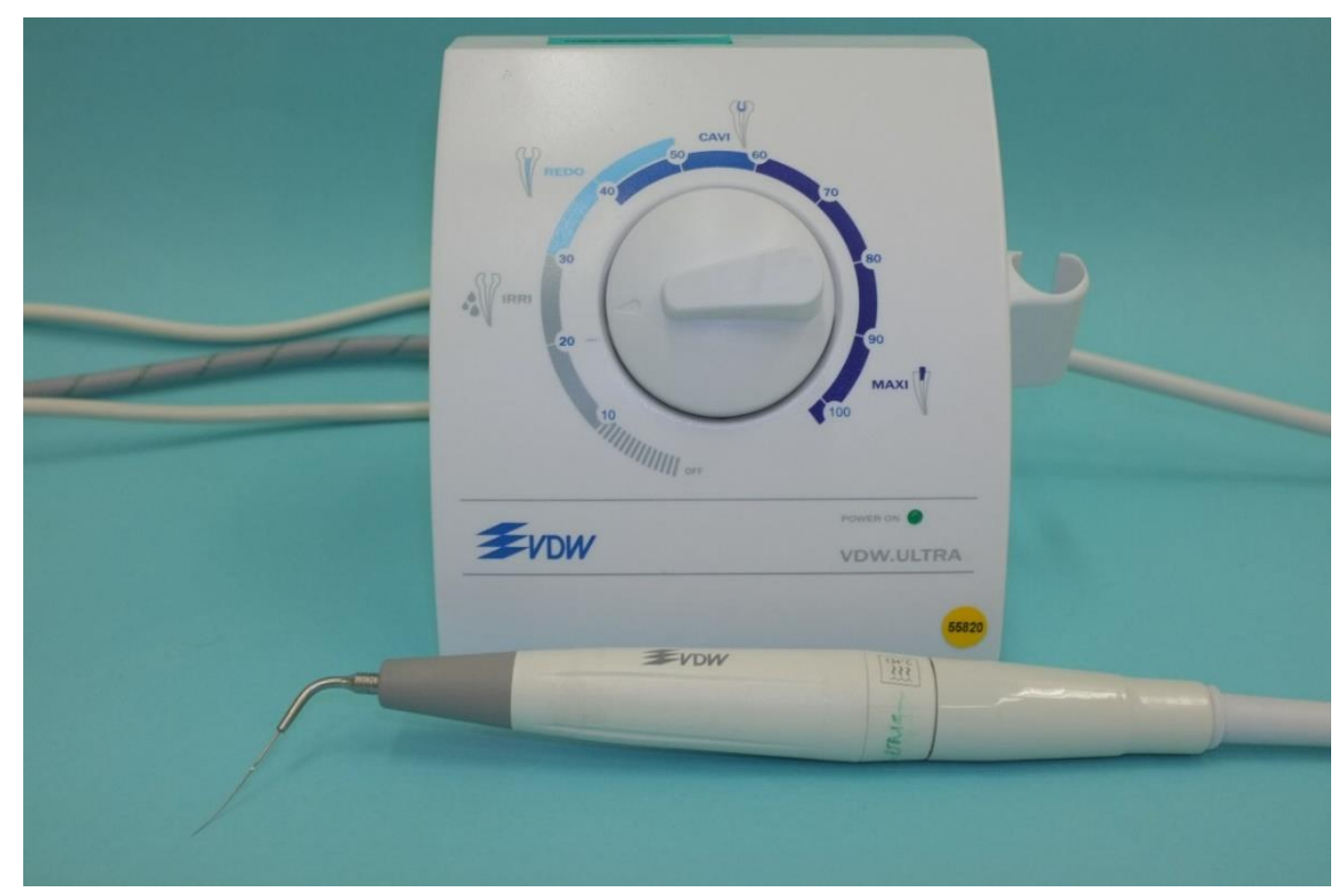

Abbildung 6: VDW Ultra Spülgerät mit Feile der ISO-Größe 15 
In der Gruppe US-CF kam eine individuell modifizierte, ultraschallaktivierte Spülkanüle zum Einsatz (Abbildung 7). Die Aktivierung wurde mit dem Piezon Master 600 (Electronic Medical Systems, Nyon, Schweiz) durchgeführt. Das Ultraschallgerät wurde nach den Empfehlungen des Herstellers auf eine Intensität von 30\% eingestellt. Das Handstück wurde mit einem Ultraschallansatz versehen, in dessen rückseitige Krümmung ein kleines Loch gebohrt und eine Endo-EZE-Spülkanüle der Größe 30 eingeführt wurde. Diese war mit einem Perfusorschlauch (Fresenius Kabi, Bad Homburg) verbunden, an dessen anderem Ende eine mit Spülflüssigkeit gefüllte 5 -ml-Spritze befestigt war. Die ultraschallaktivierte Spülnadel wurde auf AL - $1 \mathrm{~mm}$ in den Wurzelkanal eingebracht, wobei die Spülflüssigkeit simultan appliziert wurde. Auf einen $30 \mathrm{~s}$ dauernden kombinierten Spül/Aktivierungsvorgang folgten jeweils $30 \mathrm{~s}$ Einwirkzeit.

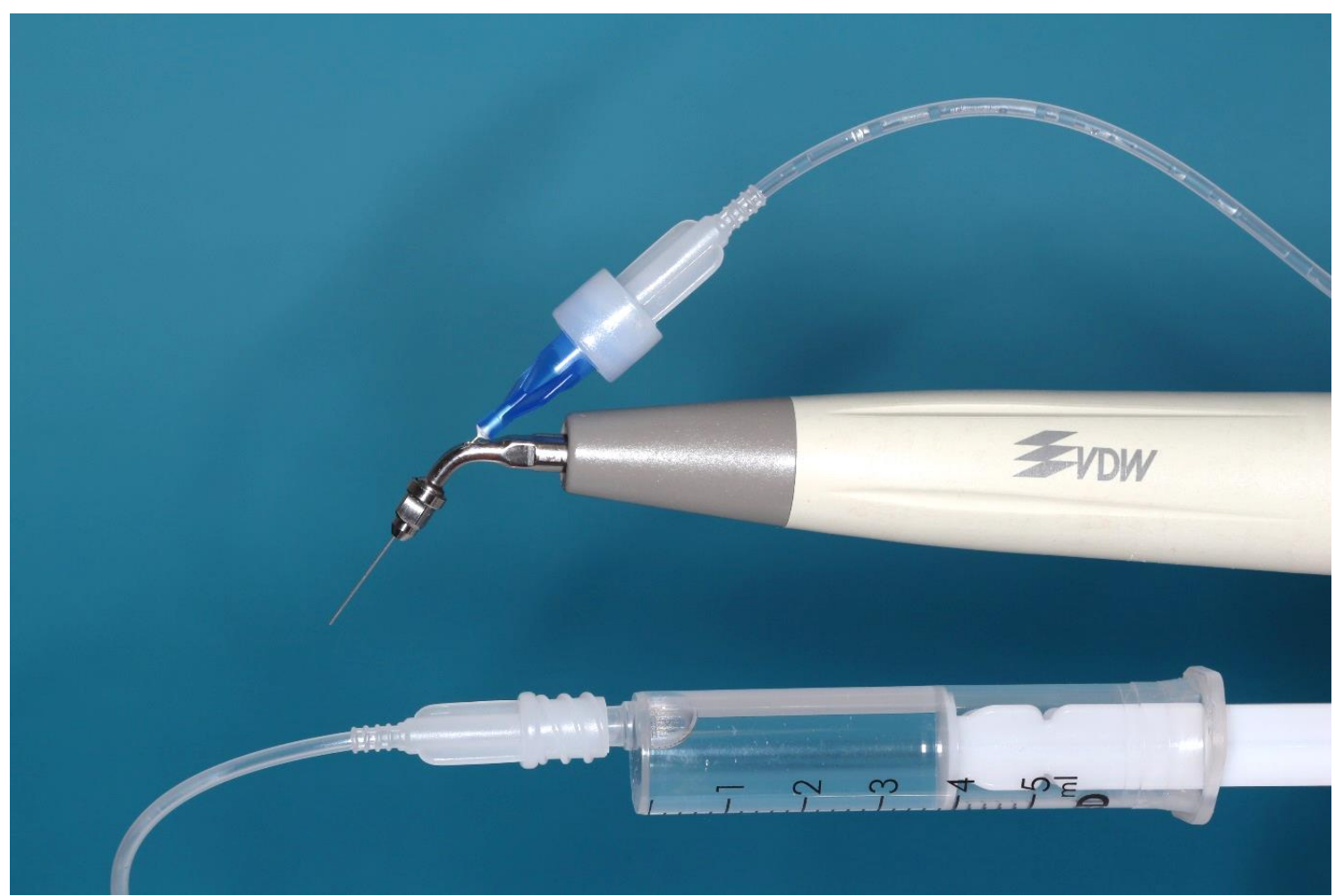

Abbildung 7: Apparatur zur kontinuierlichen Ultraschallspülung (US-CF)

\subsection{Probenentnahme und Probenkultivierung}

Es wurden jeweils zehn Prüfkörper einer Versuchsgruppe nach dem zuvor beschriebenen Protokoll gespült und direkt im Anschluss die mikrobiellen Proben entnommen. Dazu erfolgte zunächst eine Spülung mit $3 \mathrm{ml}$ 0,9\%-NaCl-Injektionslösung, um verbliebenes $\mathrm{NaOCl}$ aus dem Wurzelkanal zu entfernen sowie die Trocknung der Wurzelkanäle mit einer Papierspitze der ISO-Größe 40 (Orbis Dental, Münster). Diese Papierspitze wurde in ein 
2-ml-Eppendorf-Röhrchen gegeben, in dem sich $500 \mu \mathrm{l} \mathrm{NaCl}$ befanden. Dann wurde die Wurzelkanalwand nacheinander mit drei Hedström-Feilen der ISO-Größen 40, 45 und 50 (VDW) zirkumferent instrumentiert, bis sich in den Schneiden Dentinspäne angesammelt hatten. Diese drei Feilen wurden ebenfalls in das Eppendorf-Röhrchen gegeben, welches anschließend für $20 \mathrm{~s}$ gevortext wurde.

\subsubsection{Probenentnahme in den Versuchsgruppen}

Nach Entnahme der Instrumente und der Papierspitze erfolgte kurz vor der Probenentnahme eine erneute Durchmischung für jeweils $5 \mathrm{~s}$. Im Anschluss wurden mit einer Eppendorf-Pipette $25 \mu \mathrm{l}$ der Flüssigkeit aus dem unteren Drittel des EppendorfRöhrchens entnommen und in der Mitte einer zuvor beschrifteten Blutagarplatte mit einem Plattierspatel ausplattiert. Dieser Vorgang wurde für jedes Eppendorf-Röhrchen, also auch für jeden Prüfkörper, drei Mal durchgeführt. Entsprechend konnten für jede Gruppe abschließend 30 Blutagarplatten ausgewertet werden.

\subsubsection{Probenentnahme in der Positivkontrolle}

Die Probenentnahme aus den Wurzelkanälen der Positivkontrolle erfolgte wie in Abschnitt 4.8.1 beschrieben, außer dass die Proben mit $\mathrm{NaCl}$ Lösung auf 1:200 verdünnt wurden. Nachdem die verdünnten Proben für 20 s gevortext worden waren, erfolgten ebenfalls die Entnahme von $25 \mu \mathrm{l}$ und das Ausplattieren auf einer Blutagarplatte. Dieser Vorgang wurde wie bei den Versuchsproben pro Prüfkörper drei Mal durchgeführt. Alle Blutagarplatten kamen direkt im Anschluss an die Probenentnahme bei $37^{\circ} \mathrm{C}$ für $24 \mathrm{~h}$ zur Inkubation in den Brutschrank.

\subsection{Auswertung der Proben}

Nach einer Inkubation von $24 \mathrm{~h}$ wurden die Blutagarplatten digital fotografiert und die Auszählung der Koloniebildenden Einheiten (KBE) erfolgte mit Hilfe der Software OpenCFU (Quentin Geissmann, London, England). Abbildung 8 zeigt eine Blutagarplatte mit Bakterienkolonien. 


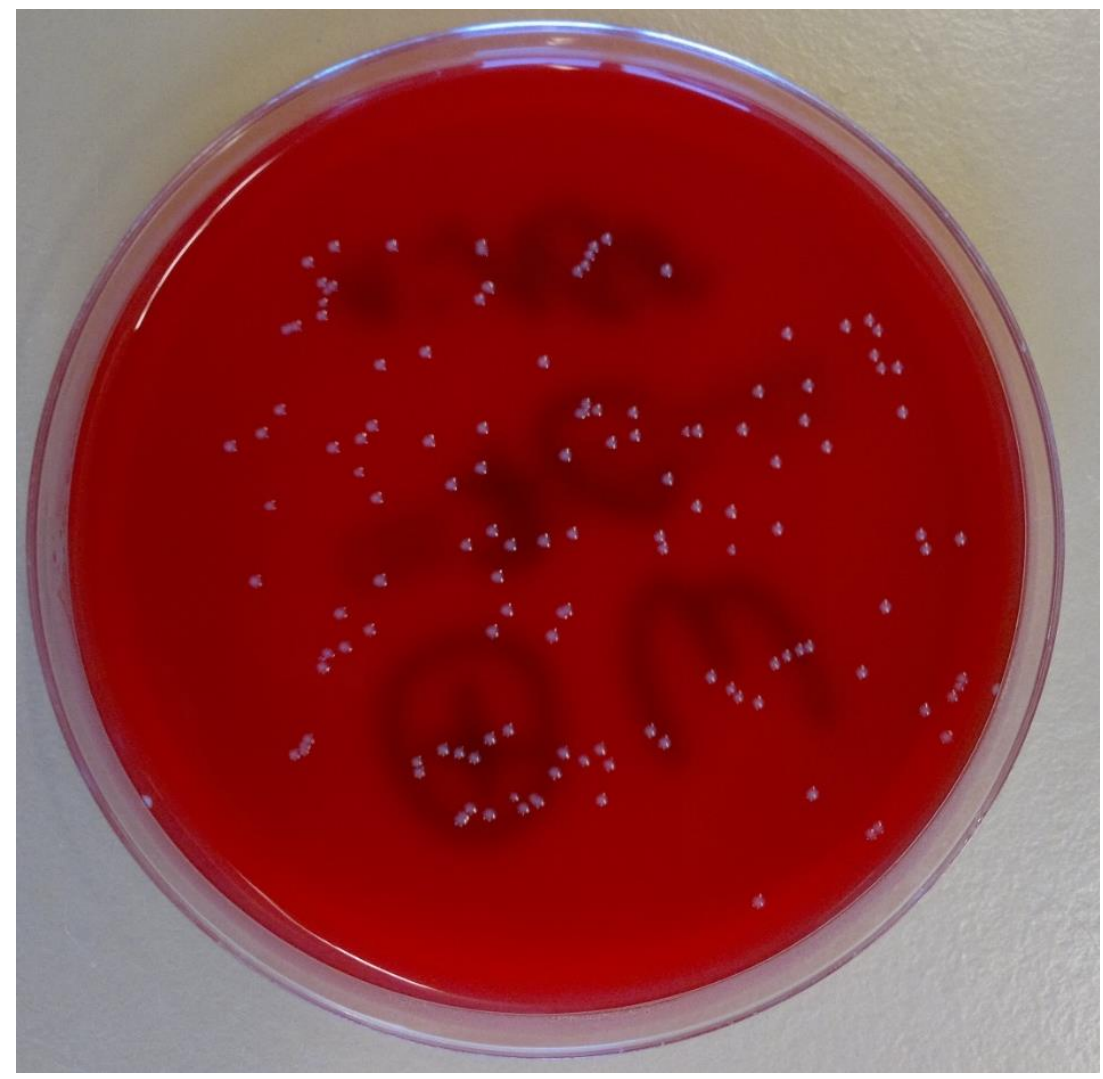

Abbildung 8: Blutagarplatte mit Bakterienkolonien

Die 1:200 verdünnten Proben der Positivkontrolle wurden auf die Ausgangskeimzahl hochgerechnet, um eine Vergleichbarkeit mit den unverdünnten Proben der Versuchsgruppen zu gewährleisten. In der nachfolgenden statistischen Auswertung dienten die Keimzahlen der Positivgruppen als Referenz für die prozentuale Keimreduktion in den Versuchsgruppen.

\subsection{Nachweis der Schmierschichtentfernung und des Biofilms im Rasterelektronenmikroskop}

Um eine vollständige Entfernung der Schmierschicht vor dem Beimpfen der Proben mit E. faecalis und eine homogene Biofilmbildung durch das Infektionsprotokoll nachzuweisen, wurden zehn Zähne für die Betrachtung im REM vorbereitet. Jeweils fünf Zähne dienten zum Nachweis der Schmierschichtentfernung und fünf zum Nachweis des Biofilms.

\subsubsection{Vorbereitung der Zähne zum Nachweis der Schmierschichtentfernung}

Nach Dekoronation, Präparation der Wurzelkanäle mit Nickel-Titan-Instrumenten und Schmierschichtentfernung mit EDTA im Ultraschallbad wurden an fünf Zähnen mit einer Trennscheibe longitudinale Sollbruchstellen angelegt. Im Anschluss wurden die Zähne mit 
einem sterilen Hebel nach Bein längs gespalten. Die Wurzelhälften wurden auf Metallpins geklebt und für $24 \mathrm{~h}$ getrocknet.

\subsubsection{Vorbereitung der Zähne zum Nachweis des Biofilms}

Die mit E. faecalis infizierten Wurzelhälften wurden drei Mal in jeweils $50 \mathrm{ml} 0,9 \%-\mathrm{NaCl}-$ Lösung geschwenkt und für $24 \mathrm{~h}$ in einen Behälter mit Paraformaldehyd-Fixierlösung gegeben. Nachfolgend erfolgte die Substitution der Fixierlösung in einer aufsteigenden Alkoholreihe mit 70\%, 80\%, 90\% und 100\% Ethanol. Dann wurden die Zahnhälften mit Hilfe der Kritische-Punkt-Trocknung getrocknet und auf Metallpins geklebt. Die so vorbereiteten Proben wurden unter Argon-Atmosphäre mit einem Sputterfilm aus Gold versehen (SEM Coating System, Fisons Instruments, East Sussex, UK).

\subsubsection{Rasterelektronenmikroskopische Untersuchung}

Mit einem REM (Zeiss Ultra Plus, Carl Zeiss AG, Oberkochen) wurden Mikrofotografien beider Gruppen in 500facher und 5000facher Vergrößerung angefertigt. 


\section{$5 \quad$ Ergebnisse}

\subsection{Rasterelektronenmikroskopische Auswertung}

\subsubsection{Nachweis der Schmierschichtentfernung}

Zum Nachweis der Schmierschichtentfernung wurden Mikrofotografien der zehn Zahnhälften in 500facher Vergrößerung angefertigt. Die Mikrofotografien belegen die vollständige Entfernung der Schmierschicht mit 17\%-EDTA-Spülung und 17\%-EDTAUltraschallbad (Abbildung 9).

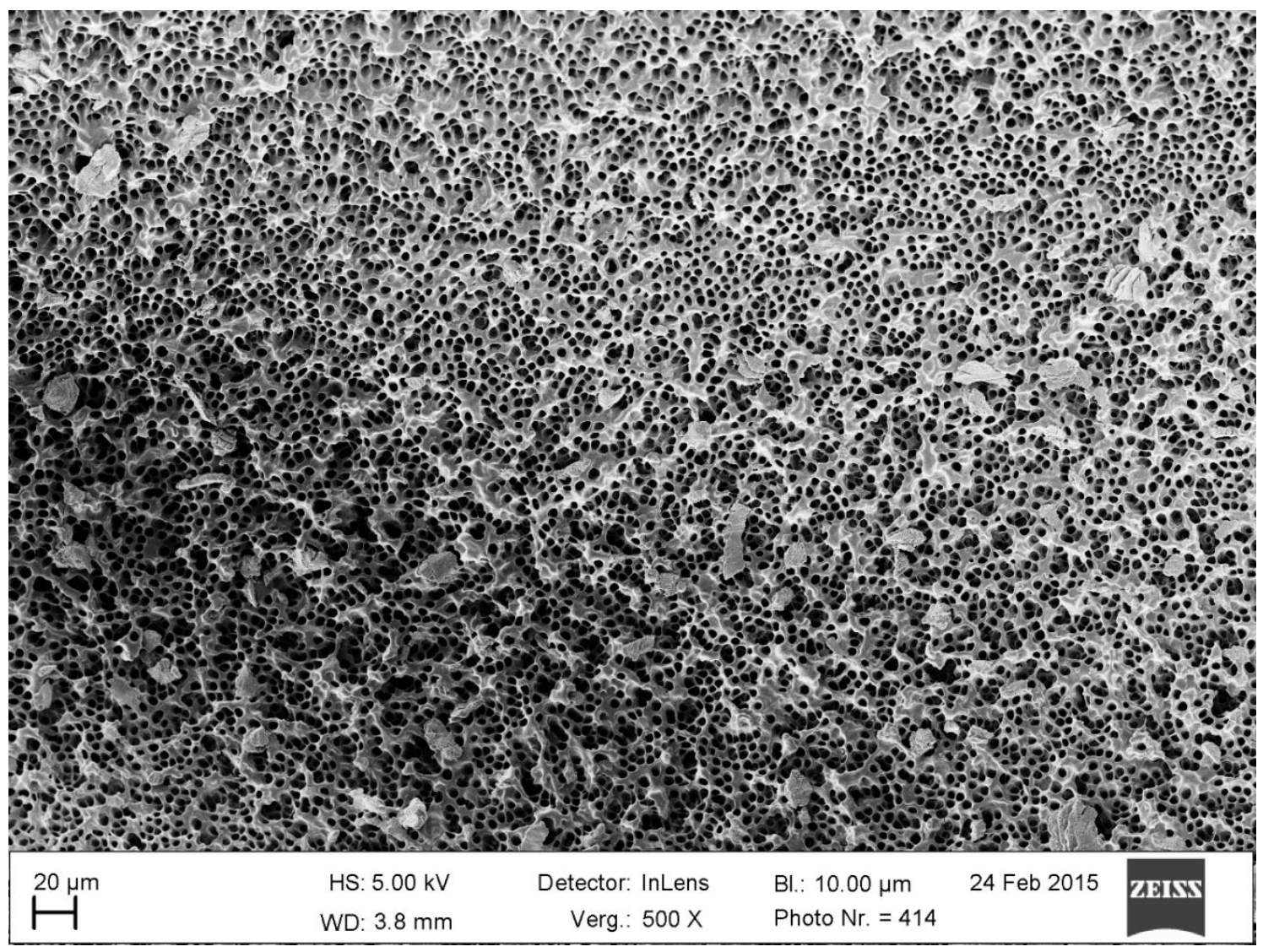

Abbildung 9: Mikrofotografie einer Wurzelkanaloberfläche nach Schmierschichtentfernung (500fache Vergrößerung). HS = Hochspannung, $\mathrm{Bl}=$ Blende, $\mathrm{WD}=$ Arbeitsabstand

\subsubsection{Nachweis des Biofilms}

Zum Nachweis der Biofilmbildung nach der Infektion mit E. faecalis und $72 \mathrm{~h}$ Inkubation wurden Mikrofotografien der zehn Zahnhälften in 5000facher Vergrößerung angefertigt. Sämtliche Fotografien zeigen eine dichte Besiedelung der Wurzelkanaloberflächen mit E. faecalis. Abbildung 10 zeigt eine von E. faecalis besiedelte Wurzelkanalwand mit der typischen tubulären Struktur des Dentins und Bakterien in den Dentinkanälchen. 


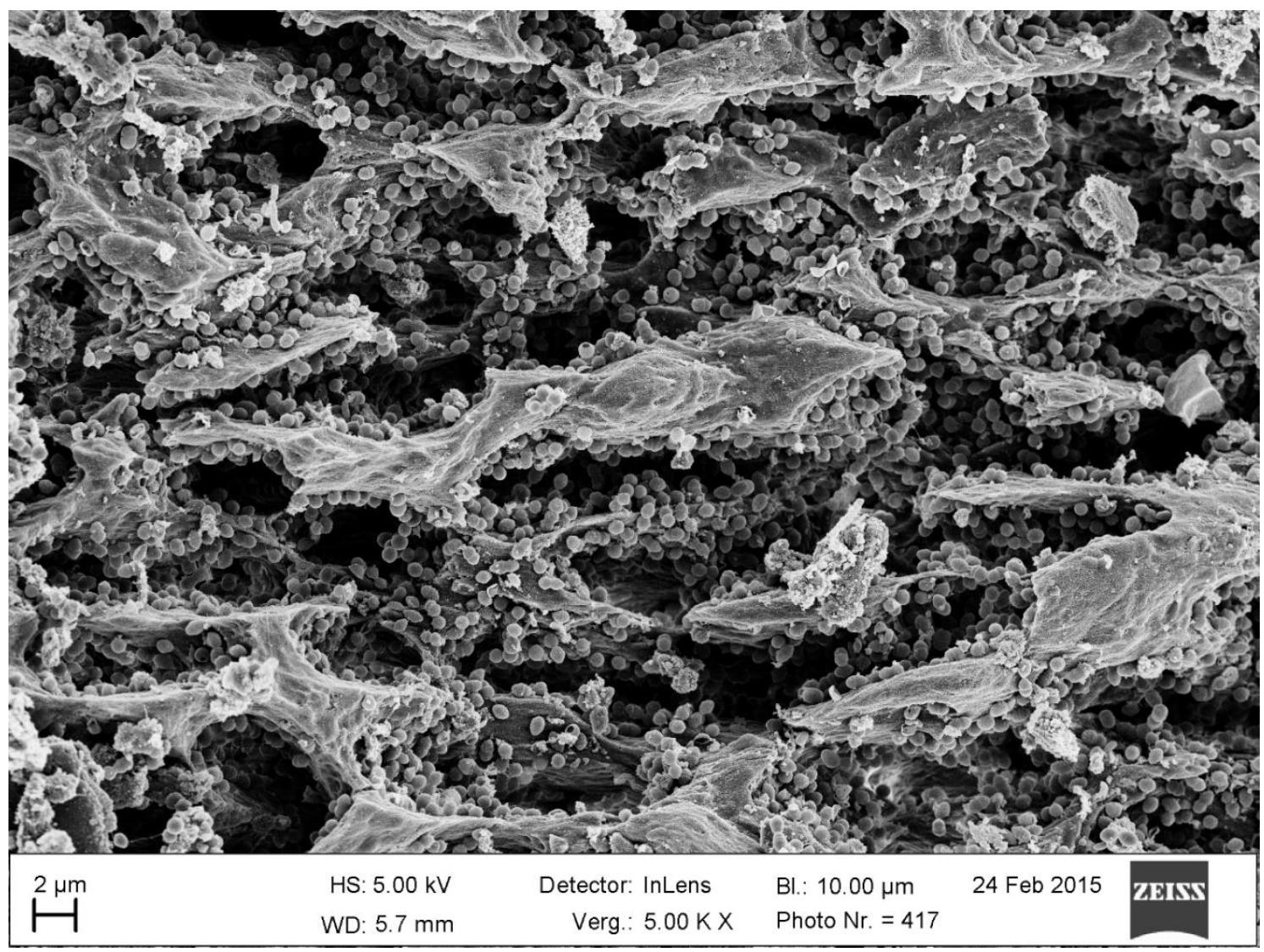

Abbildung 10: Wurzelkanaloberfläche mit E. faecalis-Biofilm (5000fache Vergrößerung). HS = Hochspannung, $\mathrm{Bl}=$ Blende, $\mathrm{WD}=$ Arbeitsabstand

\subsection{Deskriptive Auswertung}

Die folgenden Darstellungen sowie alle statistischen Berechnungen wurden mit Hilfe der Software Statistica 10 (StatSoft, Tulsa, OK, USA) erstellt. Die Berechnung der nichtparametrischen Verfahren erfolgte in SAS 9.2 mit Hilfe des SAS-Makros F1-LD-F1 (Brunner et al. 2002). Bei der Auswertung der Negativkontrolle zeigte sich kein Bakterienwachstum, bei allen Proben der Positivkontrolle waren die Blutagarplatten dicht mit E. faecalis besiedelt. In den experimentellen Gruppen fand eine signifikante Reduktion der KBE im Vergleich zur Positivkontrolle statt. In Tabelle 3 sind Medianwerte, Mittelwerte, Standardabweichungen, Standardfehler und Konfidenzintervalle der KBE der einzelnen Versuchsgruppen dargestellt. Bei der Betrachtung der Mittelwerte zeigte sich eine Reduktion der Keimzahl um 99,6\% in der Gruppe Handspülung, um 98,9\% in der Gruppe Schall, um 99,2\% in der Gruppe US-IF und um 99,9\% in der Gruppe US-CF in Bezug auf die Positivkontrolle. 
Tabelle 3: Darstellung von Median, Mittelwert, Standardabweichung, Standardfehler und Konfidenzintervall der ausgezählten Koloniebildenden Einheiten. Negativ $=$ Negativkontrolle, Positiv $=$ Positivkontrolle, Hand $=$ Handspülung, Schall $=$ Schallaktivierung, US-IF $=$ Intermittierende Ultraschallaktivierung, US-CF $=$ Kontinuierliche Ultraschallaktivierung, $\mathrm{KBE}=$ Koloniebildende Einheiten, $\mathrm{SD}=$ Standardabweichung, $\mathrm{SE}=$ Standardfehler, $\mathrm{KI}=$ Konfidenzintervall

\begin{tabular}{|c|c|c|c|c|c|c|}
\hline Gruppe & $\begin{array}{l}\text { Median } \\
\text { KBE }\end{array}$ & $\begin{array}{c}\text { Mittelwert } \\
\text { KBE }\end{array}$ & SD & $\mathrm{SE}$ & $\begin{array}{c}\mathrm{KI} \\
(-95 \%)\end{array}$ & $\begin{array}{c}\mathrm{KI} \\
(+95 \%)\end{array}$ \\
\hline Negativ & 0 & 0 & 0 & 0 & 0 & 0 \\
\hline Positiv & 130300 & 141073 & 94657 & 17282 & 105727 & 176419 \\
\hline Hand & 206,5 & 544,6 & 730,0 & 133,3 & 272,0 & 817,2 \\
\hline Schall & 87,0 & 2022 & 5842 & 1067 & $-160,0$ & 4203 \\
\hline US-IF & 147,0 & 1081 & 1587 & 289,7 & 488,8 & 1674 \\
\hline US-CF & 67,0 & 197,7 & 289,1 & 52,8 & 89,7 & 305,7 \\
\hline
\end{tabular}


Abbildung 11 zeigt die Anzahl der KBE der Negativkontrolle, der Positivkontrolle und der experimentellen Gruppen auf den Blutagarplatten anhand einer Kastengrafik (,,box plot“).

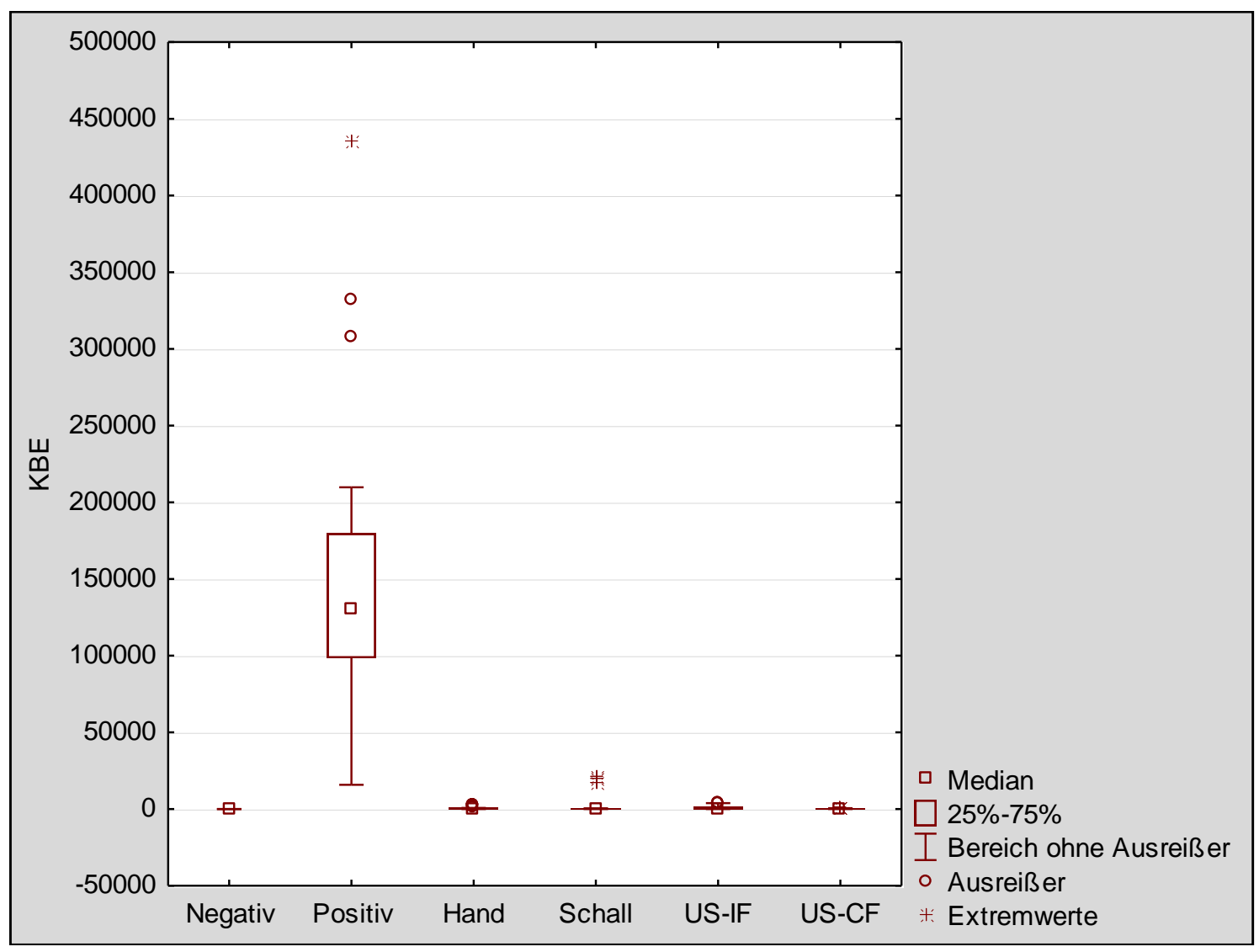

Abbildung 11: ,box plots“der Gruppen im Vergleich. KBE = Koloniebildende Einheiten, Negativ = Negativkontrolle, Positiv $=$ Positivkontrolle, Hand $=$ Handspülung, Schall $=$ Schallaktivierung, US $\mathrm{IF}=$ Intermittierende Ultraschallaktivierung, US-CF $=$ Kontinuierliche Ultraschallaktivierung

Um die Ergebnisse der experimentellen Gruppen grafisch besser veranschaulichen zu können, wurde in Abbildung 12 die Skalierung der Y-Achse so verändert, dass auf die Darstellung der Positivkontrolle und der drei Ausreißer der Gruppe Schall verzichtet wurde. Aus dieser Darstellung lässt sich entnehmen, dass die Medianwerte sich nicht annähernd in der Mitte der „box plots“ befinden. Damit ist das wesentliche Kriterium für eine Gaußsche Normalverteilung der Ergebnisse nicht erfüllt und die Ergebnisse sind für parametrische Testverfahren nicht geeignet. Aus diesem Grunde wurde für die in Kapitel 5.3 beschriebene statistische Auswertung ein nichtparametrisches Testverfahren gewählt. 


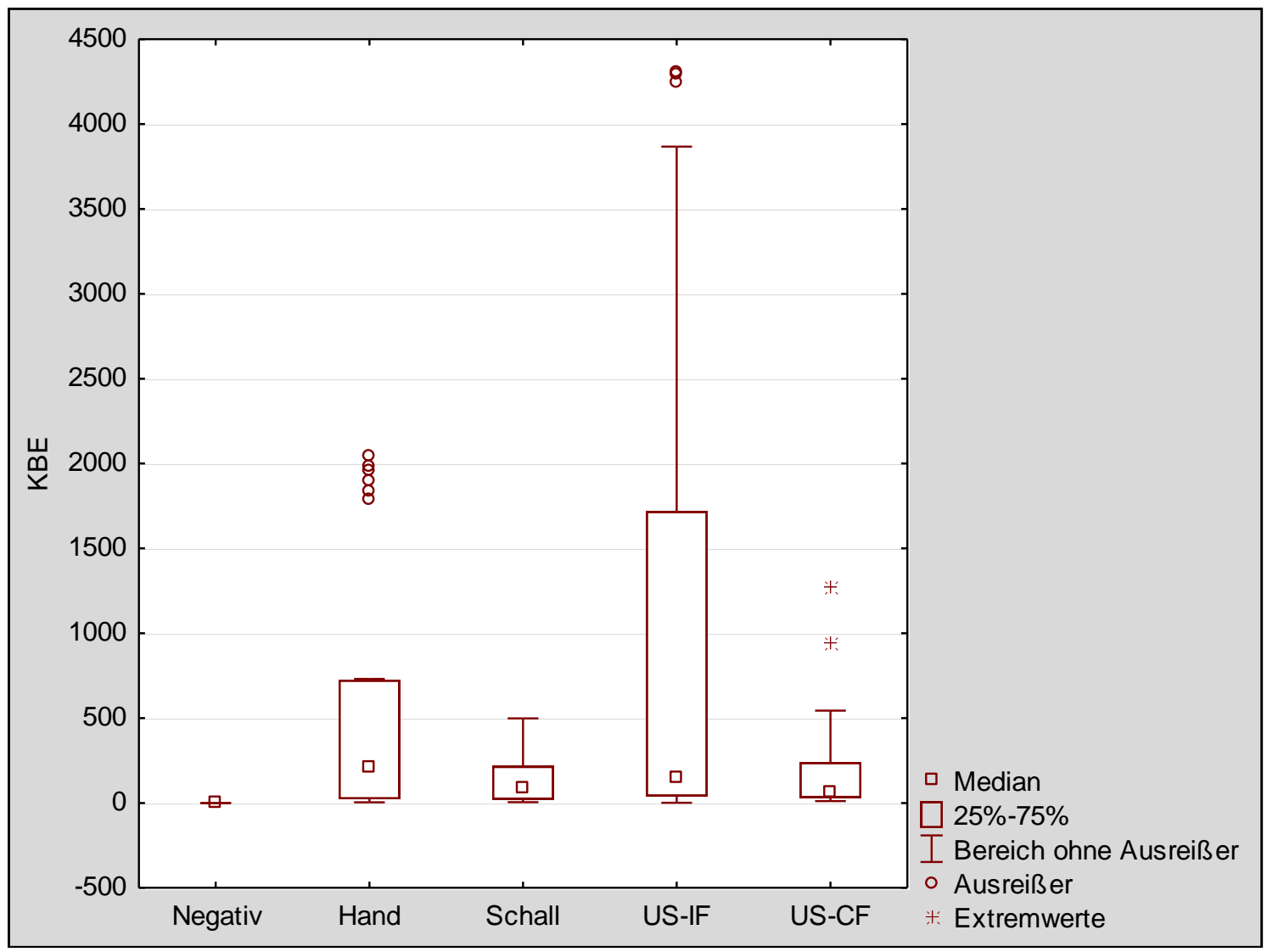

Abbildung 12: „,boxplots"der experimentellen Gruppen ohne Positivkontrolle und der Messwerte des Zahns Nummer sechs der Gruppe Schall. $\mathrm{KBE}=$ Koloniebildende Einheiten, Negativ = Negativkontrolle, Hand $=$ Handspülung, Schall $=$ Schallaktivierung, US-IF $=$ Intermittierende Ultraschallaktivierung, US-CF = Kontinuierliche Ultraschallaktivierung

Zur Vorbereitung der statistischen Auswertung wurden aus den Messwerten mittlere Ränge generiert und in relative Effekte (RTE $=$,relative treatment effects") transformiert. Unterschiedlich große RTE zwischen verschiedenen Gruppen geben Aufschluss darüber, ob in einer Gruppe tendenziell größere Messwerte auftreten als in einer anderen Gruppe. Die ermittelten RTE für die verschiedenen Versuchsgruppen sind in Tabelle 4 zusammengefasst. 
Tabelle 4: Darstellung der mittleren Ränge, der Gruppengröße und der RTE der Versuchsgruppen. RTE $=$,relative treatment effects“, Schall $=$ Schallaktivierung, US-IF $=$ Intermittierende Ultraschallaktivierung, US-CF = Kontinuierliche Ultraschallaktivierung

\begin{tabular}{|l|l|l|l|}
\hline Gruppe & Mittlere Ränge & Gruppengröße & RTE \\
\hline Positivkontrolle & 135,33 & 10 & 0,90 \\
\hline Handspülung & 65,08 & 10 & 0,43 \\
\hline Schall & 55,67 & 10 & 0,37 \\
\hline US-IF & 66,62 & 10 & 0,44 \\
\hline US-CF & 54,80 & 10 & 0,36 \\
\hline
\end{tabular}

\subsection{Statistische Auswertung}

Mit den in Tabelle 4 ermittelten RTE wurde eine Varianzanalyse (ANOVA $=$,analysis of variance") zur Überprüfung der Gleichheit der fünf unterliegenden Verteilungen durchgeführt. Das Testverfahren berücksichtigt dabei die in Kapitel 4.8.1 beschriebenen drei wiederholten Messungen eines jeden Zahnes. Wie in Tabelle 5 ersichtlich ist, besteht ein hoch signifikanter Unterschied zwischen den Verteilungen der fünf Gruppen ( $p<0,0001)$.

Tabelle 5: Varianzanalyse (ANOVA = ,analysis of variance") über alle Versuchsgruppen. Dargestellt sind F-Wert, Freiheitsgrade und p-Wert. DF1 = Freiheitsgrad zwischen den Gruppen, DF2 = Freiheitsgrad innerhalb der Gruppen

\begin{tabular}{|c|c|c|c|c|}
\hline & F-Wert & DF1 & DF2 & p-Wert \\
\hline Alle Gruppen & 11,83 & 3,16 & 32,86 & $<0,0001$ \\
\hline
\end{tabular}

Um Unterschiede zwischen einzelnen Gruppen zu analysieren, wurden multiple Vergleiche zwischen den Gruppen in einer weiteren ANOVA durchgeführt. Die Ergebnisse sind in Tabelle 6 zusammengefasst. Alle vier Spülmethoden führten gegenüber der Positivkontrolle zu einer hoch signifikanten Keimreduktion an E. faecalis $(\mathrm{p}<0,0001)$.

Die Paarvergleiche der experimentellen Gruppen ergaben keine signifikanten Unterschiede. Eine Adjustierung der p-Werte für multiples Testen resultierte in keinem der Vergleiche in einer Änderung der Signifikanz der Ergebnisse. Daher war keine weitere Adjustierung der pWerte für multiples Testen notwendig ( $p>0,05)$. 
Tabelle 6: Multiple einfaktorielle Varianzanalysen. Paarvergleiche zwischen den Versuchsgruppen mit Angabe von F-Werten, Anzahl der Freiheitsgrade und $\mathrm{p}$-Werten. DF $=$ Freiheitsgrade, Schall $=$ Schallaktivierung, US-IF $=$ Intermittierende Ultraschallaktivierung, US-CF $=$ Kontinuierliche Ultraschallaktivierung

\begin{tabular}{|l|l|l|l|}
\hline Paarvergleich & F Wert & DF & p-Wert \\
\hline Positivkontrolle vs. Handspülung & 32,113 & 1 & $<\mathbf{0 , 0 0 0 1}$ \\
\hline Positivkontrolle vs. Schall & 51,793 & 1 & $<\mathbf{0 , 0 0 0 1}$ \\
\hline Positivkontrolle vs. US-IF & 26,239 & 1 & $<\mathbf{0 , 0 0 0 1}$ \\
\hline Positivkontrolle vs. US-CF & 72,692 & 1 & $<\mathbf{0 , 0 0 0 1}$ \\
\hline Handspülung vs. Schall & 0,341 & 1 & 0,9314 \\
\hline Handspülung vs. US-IF & 0,007 & 1 & 0,5591 \\
\hline Handspülung vs. US-CF & 0,467 & 1 & 0,4944 \\
\hline Schall vs. US-CF & 0,004 & 1 & 0,5174 \\
\hline US-IF vs. Schall & 0,419 & 1 & 0,4573 \\
\hline US-IF vs. US-CF & 0,553 & 1 & 0,9506 \\
\hline
\end{tabular}




\section{Diskussion}

\subsection{Diskussion der Methode}

In der vorliegenden Studie wurde die antibakterielle Wirksamkeit verschiedener Techniken für die Aktivierung von $1 \% \mathrm{NaOCl}$ auf einen intrakanalären $E$. faecalis-Biofilm untersucht. Der Versuchsaufbau orientierte sich an bereits etablierten Wurzelkanal-Biofilm-Modellen verschiedener Autoren (Brito et al. 2009; Bhuva et al. 2010; Pasqualini et al. 2010) und wurde im Rahmen von Vorversuchen modifiziert bzw. ergänzt.

\subsubsection{Herstellung der Prüfkörper}

Die vorliegende Biofilm-Studie wurde in vitro an extrahierten humanen Zähnen durchgeführt, um eine möglichst gute Übertragbarkeit der Ergebnisse auf die klinische Situation zu erreichen. Die Verwendung einwurzeliger, gerader Zähne ermöglichte die Präparation der Wurzelkanäle auf eine standardisierte Länge und Konizität.

Dentintubuli werden beim Vorliegen einer infizierten Pulpanekrose innerhalb kurzer Zeit von Bakterien besiedelt (Haapasalo und Ørstavik 1987; Love und Jenkinson 2002), wodurch die Desinfektion des Wurzelkanalsystems erschwert wird. Auf den REM-Fotografien ließ sich eine solche Besiedelung der Wurzelkanaloberflächen mit einem E. faecalis-Biofilm sowie eine Penetration der Bakterien in die Dentintubuli nachweisen.

Die Wirkung des eingesetzten Desinfektionsmittels könnte durch die Verwendung natürlicher Zähne beeinträchtigt worden sein, da Dentin aufgrund seiner hohen Pufferkapazität eine inhibitorische Wirkung gegenüber 1\% NaOCl besitzt (Sirén et al. 2000). Andere Autoren verwendeten daher künstliche Wurzelkanäle aus Kunststoff (van der Sluis et al. 2005; Townsend und Maki 2009) oder Silikon (Layton et al. 2015). Der Nachteil dieser Modelle liegt in der geringen klinischen Relevanz, da die komplexe Anatomie des Endodonts sowie seine histologische Struktur und chemischen Eigenschaften nicht berücksichtigt werden. Der Vorteil künstlicher Wurzelkanalmodelle liegt in der besseren Standardisierbarkeit der Prüfkörper, da keine anatomischen Varianzen natürlicher Zähne berücksichtigt werden müssen.

Eine weitere Möglichkeit ist der Einsatz von standardisierten Dentinblöcken aus Rinderzähnen, in die künstliche Wurzelkanäle präpariert werden (Haapasalo und Ørstavik 1987; Gründling et al. 2011). Diese Methode bietet den Vorteil, dass die Versuche in homogenen Blöcken aus zirkumpulpalem Dentin durchgeführt werden können. Diese 
künstlich präparierten Wurzelkanäle weisen weniger Unregelmäßigkeiten und anatomische Varianzen auf als ein natürlicher Wurzelkanal, die typische Dentinstruktur mitsamt der Dentintubuli bleibt aber erhalten.

In der vorliegenden Studie wurden die Wurzelkanäle mit einer standardisierten Sequenz von Nickel-Titan-Instrumenten auf eine einheitliche Länge und Konizität präpariert, um möglichst vergleichbare Kanalvolumina für die Nährlösung zu erzeugen. Die Erweiterung der Wurzelkanäle auf eine apikale Präparationsgröße von 40/.02 ermöglichte eine spannungsfreie Insertion der Spülkanülen und Instrumentenspitzen der verschiedenen Spülsysteme auf Arbeitslänge - $1 \mathrm{~mm}$, sodass ein Abfluss der Spülflüssigkeit nach koronal gewährleistet war. Die REM-Bilder belegen eine suffiziente Entfernung der präparationsbedingten Schmierschicht und eine Freilegung der Dentintubuli, sodass eine Penetration von E. faecalis in tiefere Schichten des Kanalwanddentins möglich war.

Zur besseren Handhabung und aufrechten Lagerung wurden die Zähne der experimentellen Gruppen in Prothesenkunststoff eingebettet. Durch die Versiegelung des apikalen Foramens mit Komposit wurde die Extrusion von Spülflüssigkeit verhindert. In der Mundhöhle ist das Endodont über das Foramen apicale mit den periradikulären Strukturen verbunden, sodass ein Überpressen von Debris und Spülflüssigkeiten möglich ist (Gupta et al. 2014). Da in der vorliegenden Studie die antimikrobielle Wirksamkeit verschiedener Spülmethoden und nicht die Sicherheit der Spülsysteme hinsichtlich des Überpressens von Debris und Spülflüssigkeit untersucht wurde, erfolgte die apikale Versiegelung der Prüfkörper mit Komposit, wie es auch in vorangegangenen Studien durchgeführt wurde (Gulabivala et al. 2004; Brito et al. 2009; Guerreiro-Tanomaru et al. 2015). Zusätzliche Effekte durch unterschiedliche Strömungsmuster von Spülflüssigkeiten in offenen und geschlossenen Systemen (Gulabivala et al. 2010) sowie die Möglichkeit des Überpressens von Mikroorganismen wurden durch das im vorliegenden Versuch verwendete geschlossene System nicht berücksichtigt. Systeme, welche den apikalen Gewebedruck simulieren, bilden die klinischen und anatomischen Verhältnisse des natürlichen Zahnes exakter nach als geschlossene Systeme (Peters et al. 2005). Derartige Modelle sollten bei künftigen Studien zur antimikrobiellen Wirksamkeit verschiedener Spültechniken berücksichtigt werden.

\subsubsection{Biofilm}

Die antimikrobielle Effektivität der verschiedenen Spültechniken wurde anhand eines $72 \mathrm{~h}$ alten E. faecalis-Biofilms untersucht. Dieses Bakterium ist unter anaeroben sowie aeroben Bedingungen einfach zu kultivieren, bildet in kurzer Zeit dichte Biofilme und wurde bereits 
von zahlreichen Autoren in In-vitro-Studien verwendet (Brito et al. 2009; Bhuva et al. 2010; Harrison et al. 2010; Pasqualini et al. 2010; Guerreiro-Tanomaru et al. 2015). In der Literatur werden Inkubationszeiten von $2 \mathrm{~h}$ (Pasqualini et al. 2010) bis zu $77 \mathrm{~d}$ angegeben (Distel et al. 2002). E. faecalis ist in der Lage, innerhalb eines Tages bis $\mathrm{zu} 400 \mu \mathrm{m}$ tief in die Dentintubuli zu penetrieren (Haapasalo und Ørstavik 1987) und Wurzelkanaloberflächen innerhalb von $2 \mathrm{~d}$ vollständig zu besiedeln (Distel et al. 2002). In vielen Studien zeigte sich bereits nach $72 \mathrm{~h}$ ein homogen ausgebildeter E. faecalis-Biofilm auf der gesamten Wurzeloberfläche (Gulabivala et al. 2004; Soukos et al. 2006; Bhuva et al. 2010). Daher wurde in der vorliegenden Untersuchung eine Inkubationszeit von $72 \mathrm{~h}$ gewählt. Bei längerer Kultivierung steigt die Resistenz intrakanalärer E. faecalis-Biofilme gegenüber Desinfektionsmitteln deutlich an (Wang et al. 2012; Du et al. 2014), sodass die antimikrobielle Effektivität der in der vorliegenden Studie untersuchten Spültechniken möglicherweise überschätzt wird. Dies sollte in zukünftigen Studien anhand älterer E. faecalis-Biofilme überprüft werden.

Da E. faecalis ein fakultativ anaerobes Bakterium (Gilmore 2002) ist, wurde zu Beginn der Vorversuche eine anaerobe Kultivierung des Biofilms angestrebt, um die klinischen Bedingungen im geschlossenen Wurzelkanalsystem $\mathrm{zu}$ simulieren. Im Verlauf der Vorversuche erwies sich jedoch keines der getesteten Verschlussmaterialien für die Zugangskavität als geeignet. Beim Verschluss der Wurzelkanäle mit Cavit (3M Deutschland, Neuss) wurden die Prüfkörper zu stark dehydriert, und es zeigte sich keine homogene Biofilmentwicklung. Der koronale Verschluss mit Wachs verdrängte $\mathrm{zu}$ viel Bakteriensuspension aus den Wurzelkanälen und ließ sich nach der Inkubation nur schwer und unvollständig entfernen. Daher wurde der aeroben Kultivierung des Keimes der Vorzug gegeben. Bei der Auswertung der Positivkontrollen und der REM-Aufnahmen wurden hohe Keimzahlen sowie ein homogenes Biofilmwachstum auf der Wurzelkanaloberfläche festgestellt.

\subsubsection{Spültechniken}

In allen experimentellen Gruppen wurden jeweils $6 \mathrm{ml} 1 \% \mathrm{NaOCl}$ verwendet, um standardisierte Bedingungen zu schaffen. Eine geringe NaOCl-Konzentration von $1 \%$ wird für den klinischen Gebrauch empfohlen, da sie bei ausreichender antimikrobieller Wirksamkeit eine geringere zytotoxische Wirkung als höher konzentriertes $\mathrm{NaOCl}$ aufweist (Spångberg et al. 1973). In früheren Studien wurde die Menge der Spülflüssigkeit zwischen den Versuchsgruppen nicht standardisiert (Carver et al. 2007; Brito et al. 2009; Bhuva et al. 2010). Zum Beispiel wurden in der Studie von Brito et al. (2009) in den experimentellen 
Gruppen je nach getestetem Spülsystem 20 bis $41 \mathrm{ml}$ 2,5\% NaOCl verwendet, was aufgrund der stark volumenabhängigen Desinfektionsleistung des $\mathrm{NaOCl}$ möglicherweise einen Einfluss auf das Ergebnis hatte.

Die desinfizierende Wirkung des $\mathrm{NaOCl}$ wurde in der vorliegenden Studie nach dreiminütiger Spül- und Einwirkzeit durch eine Spülung mit $3 \mathrm{ml} 0,9 \% \mathrm{NaCl}$ gestoppt. Andere Autoren verwendeten Natriumthiosulfat, um die antimikrobielle Wirkung von $\mathrm{NaOCl}$ zu stoppen (Siqueira et al. 2000; Carver et al. 2007; Retamozo et al. 2010; GuerreiroTanomaru et al. 2015). Natriumthiosulfat wird in der Industrie verwendet, um Chlor zu binden und die antimikrobielle Wirkung von $\mathrm{NaOCl}$ zu inhibieren. $\mathrm{NaCl}$ verdünnt $\mathrm{NaOCl}$ lediglich und hat keine inhibierende Wirkung auf das Agens. Möglicherweise hätte der Einsatz von Natriumthiosulfat eine etwaige prolongierte Wirkung des $\mathrm{NaOCl}$ unterbunden und die Ergebnisse des Versuchs beeinflusst.

\subsubsection{Probengewinnung}

Die antimikrobielle Effektivität unterschiedlicher Desinfektionsprotokolle kann mittels verschiedener Methoden analysiert werden. Viele Techniken (Kolorimetrie, REM, molekularbiologische Methoden) erfassen sowohl lebende als auch bereits abgetötete Mikroorganismen, obwohl für den klinischen Erfolg nur die Menge der verbleibenden, teilungsfähigen Bakterien relevant ist. In der vorliegenden Studie wurden dem Biofilm mechanisch Bakterien entnommen, durch mikrobiologische Kultivierung auf einem Kulturmedium angezüchtet und im Anschluss die Koloniebildenden Einheiten gezählt. Diese Methode wurde bereits von zahlreichen Autoren eingesetzt (Pasqualini et al. 2010; Guerreiro-Tanomaru et al. 2015; Layton et al. 2015) und hat den Vorteil, dass nur die überlebenden, teilungsfähigen Mikroorganismen gezählt werden. Problematisch ist hierbei, dass die Bakterien nach Beendigung des Desinfektionsprotokolls aus dem intrakanalären Biofilm in ein Kulturmedium überführt werden müssen, um erneut kultiviert und gezählt zu werden. Neuere Studien legen nahe, dass Mikroorganismen auf diesen Substratwechsel sensibel reagieren und es zu einer Verringerung in der Teilungsgeschwindigkeit für einen Zeitraum von 1 - $7 \mathrm{~d}$ bis hin zum Verlust der Teilungsfähigkeit kommen kann (Kishen und Haapasalo 2012). An dieser Stelle ist als relativ neue Methode die konfokale Laser-ScanningMikroskopie (CLSM) zu erwähnen. Mittels kommerziell erhältlicher Färbekits können bakterielle Biofilme von bis zu $200 \mu \mathrm{m}$ Dicke auf planen Flächen eingefärbt werden, sodass vitale Bakterien grün und abgetötete Bakterien rot fluoreszieren. Der Biofilm wird dann von einem CLSM gescannt und am Computer in ein dreidimensionales Bild überführt. Die Volumina an rot und grün fluoreszierender Fläche können im Anschluss statistisch analysiert 
werden. Diese Technik wurde ebenfalls in mehreren Studien erfolgreich eingesetzt (Distel et al. 2002; Shen et al. 2010b; Ma et al. 2011; Wang et al. 2012; Du et al. 2014). Da Bakterien unter bestimmten Umständen zwar noch vital, aber für einen bestimmten Zeitraum nicht mehr teilungsfähig sind (Shen et al. 2010a), ist diese Nachweismethode differenzierter als die mikrobiologische Kultivierung und kommt als Alternative und zur Weiterentwicklung des vorliegenden Studiendesigns in Frage.

Zum Nachweis eines homogenen Biofilmwachstums und zum Nachweis der Schmierschichtentfernung wurden in der vorliegenden Studie zusätzlich REM-Bilder angefertigt. Bei der Dehydrierung der Proben mittels der Kritische-Punkt-Trocknung bleiben die Zellkörper der Bakterien in Form und Volumen unverändert (Kishen und Haapasalo 2012). Problematisch ist hingegen, dass die extrazelluläre Polysaccharidmatrix der Bakterien dabei nahezu vollständig verloren geht und der Biofilm dadurch seine Struktur verliert (Sutton et al. 1994). Aufgrund der genauen Darstellung und Identifikation der Zellkörper der Bakterien im REM wurde diese Methode dennoch in vorangegangenen Studien zum Nachweis bakterieller Biofilme genutzt (Distel et al. 2002; Hockett et al. 2008; Bhuva et al. 2010; Gründling et al. 2011; Ordinola-Zapata et al. 2014) und für den vorliegenden Versuch übernommen.

Für die mikrobiologische Kultivierung muss aus jedem Zahn eine Bakteriensuspension möglichst gleicher Menge und Dichte gewonnen werden. Hockett et al. (2008) instrumentierten die mit $0,5 \mathrm{ml} \mathrm{NaCl}$ gefüllten Wurzelkanäle mit K-Feilen, um einen Dentinabrieb an der Kanalwand zu erzeugen. Im Anschluss wurde der Kanalinhalt mittels Papierspitzen aufgenommen. Übergelaufene Lösung vom Befüllen der Wurzelkanäle und die zum Trocknen benutzten Papierspitzen wurden gemeinsam in ein Eppendorf-Röhrchen gegeben und weiterverarbeitet. Da bei dieser Methode sowohl planktonische Bakterien als auch verbleibender Biofilm und infiziertes Dentin als Probe gewonnen werden, wurde sie geringfügig modifiziert und für den vorliegenden Versuch übernommen. Um eine größere Menge an Dentinspänen zu gewinnen, wurden die Proben mit Hilfe von drei HedströmFeilen der ISO-Größen 40, 45 und 50 entnommen, anstatt mit einer K-Feile der ISO-Größe 30.

\subsection{Diskussion der Ergebnisse}

Keine der untersuchten Spültechniken führte zu einer vollständigen Elimination von E. faecalis aus dem Wurzelkanalsystem. Dennoch erzielten sowohl die manuelle Spültechnik als auch die schall- und ultraschallaktivierte Wurzelkanalspülung gegenüber der Positivkontrolle 
eine signifikante Reduktion der Bakterienanzahl. Dies verdeutlicht, dass 1\%iges $\mathrm{NaOCl}$ über eine signifikante antibakterielle Effektivität verfügt. Die schall- bzw. ultraschallaktivierten Spülungen ergaben gegenüber der statischen Handspülung keine signifikante Verbesserung der antimikrobiellen Wirksamkeit. Unter den Bedingungen dieser In-vitro-Studie zeigten Konzentration und Volumen der Spülflüssigkeit einen größeren Einfluss als die Art der Applikation bzw. die Aktivierung.

\subsubsection{Vergleich der Handspülung mit schall- und ultraschallaktivierten Methoden}

Die vorliegenden Resultate decken sich mit den Ergebnissen anderer In-vitro-Studien. Bhuva et al. (2010) testeten die Desinfektionswirkung einer intermittierenden Ultraschallspülung mit $\mathrm{NaOCl}$ auf einen $72 \mathrm{~h}$ alten E. faecalis-Biofilm. Die Studie wurde an geraden, extrahierten menschlichen Zähnen durchgeführt. Die intermittierende Ultraschallspülung mit $\mathrm{NaOCl}$ wies keine bessere antibakterielle Wirksamkeit als die konventionelle Handspülung mit $\mathrm{NaOCl}$ auf. Zu einem ähnlichen Ergebnis kamen Guerreiro-Tanomaru et al. (2015) in einer Studie an geraden, menschlichen Zähnen. Es bestanden keine signifikanten Unterschiede in der desinfizierenden Wirkung der intermittierenden Ultraschallspülung im Vergleich zur Handspülung mit $\mathrm{NaOCl}$ auf einen $21 \mathrm{~d}$ alten E. faecalis-Biofilm. Wie im vorliegenden Versuch erwies sich nicht die Applikations- und Aktivierungsmethode der Spülflüssigkeit als ausschlaggebend für eine erfolgreiche Kanaldesinfektion, sondern die Auswahl einer geeigneten Spülflüssigkeit. Sämtliche Spülprotokolle mit $\mathrm{NaOCl}$ zeigten sich den Spülprotokollen mit $\mathrm{NaCl}$ überlegen (Guerreiro-Tanomaru et al. 2015). In einer weiteren Studie wurde die Desinfektionswirkung der Handspülung mit der einer schallaktivierten Spülung (EndoActivator) unter Verwendung von $\mathrm{NaOCl}$ und Kochsalzlösung verglichen (Brito et al. 2009). Es wurden extrahierte, gerade, menschliche Zähne verwendet, die über 7 d mit E. faecalis inkubiert wurden. Während die Anwendung von $\mathrm{NaOCl}$ eine signifikant effektivere antibakterielle Wirksamkeit als $\mathrm{NaCl}$ aufwies, bestanden zwischen der Handspülung und der Schallaktivierung keine signifikanten Unterschiede bezüglich der antibakteriellen Wirksamkeit. Auch Pasqualini et al. (2010) führten eine Biofilm-Studie zur Desinfektionswirkung von $\mathrm{NaOCl}$ in Verbindung mit Schallaktivierung mit dem EndoActivator durch. Der Versuch fand an geraden Wurzelkanälen extrahierter Zähne statt. Im Gegensatz zum vorliegenden Versuch und den Ergebnissen anderer Autoren war die schallaktivierte Spülung effizienter als Handspülung alleine. Die Ergebnisse von Pasqualini et al. (2010) decken sich nicht mit denen der vorliegenden Studie, bei der keine Unterschiede in der antimikrobiellen Wirksamkeit der verschiedenen Applikationsarten der Spülflüssigkeit festgestellt wurden. Auffällig ist, dass der Versuch von Pasqualini et al. (2010) mit einem sehr 
jungen E. faecalis-Biofilm ( $2 \mathrm{~h}$ Inkubation bei $37^{\circ} \mathrm{C}$ ) durchgeführt wurde. Daher ist es fraglich, ob sich die Ergebnisse auf die vorliegende Studie übertragen lassen.

Betrachtet man die Desinfektionwirkung von mechanisch aktiviertem $\mathrm{NaOCl}$ und der konventionellen Handspülung im In-vivo-Versuch, werden die Ergebnisse der In-vitroVersuche größtenteils bestätigt. Cohenca et al. (2013) untersuchten die antimikrobielle Wirksamkeit der Handspülung und der intermittierenden Ultraschallspülung mit $\mathrm{NaOCl}$ an Prämolaren von Hunden, an denen eine apikale Parodontitis induziert wurde. Nach der Abschlussspülung wurden die Wurzelkanäle auf grampositive und gramnegative Bakterien getestet, wobei sich zwischen der Handspülung und der kontinuierlichen Ultraschallspülung mit $\mathrm{NaOCl}$ keine signifikanten Unterschiede ergaben. Paiva et al. (2013) führten eine klinische Studie an einwurzeligen menschlichen Zähnen mit apikaler Parodontitis durch. Dabei wurde untersucht, ob eine zusätzliche NaOCl-Abschlussspülung mittels intermittierender Ultraschallspülung eine Keimreduktion herbeiführte. Die Auswertung der Bakterienspezies und der Bakterienlast wurde mittels Polymerasekettenreaktion (PCR) durchgeführt. Zwischen der Gruppe mit intermittierender Ultraschallspülung und der Gruppe ohne Abschlussspülung bestanden keine signifikanten Unterschiede hinsichtlich der Anzahl der überlebenden Bakterien und der Anzahl der nachweisbaren Bakterienspezies. Im Gegensatz dazu ermittelten Carver et al. (2007) in einer klinischen Studie an Unterkiefermolaren mit apikaler Parodontitis eine signifikant bessere antimikrobielle Effektivität der kontinuierlichen Ultraschallspülung mit NaOCl gegenüber der Handspülung. Die von Carver et al. (2007) entwickelte ultraschallaktivierte Spülnadel diente als Vorbild für die Apparatur zur kontinuierlichen Ultraschallspülung im vorliegenden Versuch. Carver et al. (2007) führten in der Gruppe zur kontinuierlichen Ultraschallspülung eine zusätzliche Abschlussspülung mit $15 \mathrm{ml} \mathrm{6 \%} \mathrm{NaOCl}$ durch, während die Wurzelkanäle, die manuell gespült wurden, keine weitere Behandlung erhielten. Die daraus resultierende größere Menge an Spüllösung in der Gruppe „kontinuierliche Ultraschallspülung“ ist möglicherweise der Grund für die überlegene Desinfektionsleitung in dieser Versuchsgruppe. Des Weiteren lässt der experimentelle Versuchsaufbau der vorliegenden Studie nur bedingt Vergleiche mit der klinischen Studie von Carver et al. (2007) zu.

\subsubsection{Vergleich von Schall- und Ultraschallaktivierung}

Im vorliegenden Versuch ergaben sich zwischen der Schallspülung sowie der kontinuierlichen und intermittierenden Ultraschallspülung keine signifikanten Unterschiede in der antibakteriellen Wirksamkeit. Andere Autoren kamen allerdings zu unterschiedlichen Ergebnissen. Ordinola-Zapata et al. (2014) untersuchten in einer experimentellen Studie die 
antibakterielle Wirkung einer Schallspülung und einer intermittierenden Ultraschallspülung mit $\mathrm{NaOCl}$ auf einen Polyspezies-Biofilm. Der Biofilm wurde auf Dentinscheiben boviner Herkunft etabliert, die von einem Probanden für $72 \mathrm{~h}$ in der Mundhöhle getragen wurden. Nach 2 d Inkubation in einem Nährmedium wurden die Dentinscheiben nach einem standardisierten Protokoll mit schall- oder ultraschallaktiviertem $\mathrm{NaOCl}$ desinfiziert. Im Gegensatz zur vorliegenden Studie erfolgte in der Gruppe ,intermittierende Ultraschallspülung“" eine signifikant bessere Reduktion des bakteriellen Biofilms als in der Gruppe „Schallspülung“. Ordinola-Zapata et al. (2014) etablierten einen $72 \mathrm{~h}$ alten Polyspezies-Biofilm in der Mundhöhle, wohingegen in der vorliegenden Studie ein Monospezies-Biofilm (E. faecalis) verwendet wurde. Polyspezies-Biofilme weisen eine höhere Virulenz und Resistenz auf als Monospezies-Biofilme (Seth et al. 2012). Des Weiteren werteten die Autoren ihre Proben durch eine quantitative Bestimmung verbleibender Biofilmareale in REM-Bildern aus, wobei in der vorliegenden Studie die überlebenden, teilungsfähigen Bakterien durch Kultivierungsmethoden quantifiziert wurden. Diese Unterschiede in der Methodik sind eine mögliche Erklärung für die abweichenden Ergebnisse.

In einer klinischen Studie von Rico-Romano et al. (2016) an ein- und mehrwurzeligen Zähnen mit apikaler Parodontitis an 120 Patienten wurde die Spüllösung $(\mathrm{NaOCl})$ während der chemomechanischen Aufbereitung der Wurzelkanäle entweder mit Schall oder mit intermittierender Ultraschallspülung aktiviert. Vor und nach der Wurzelkanalbehandlung wurden mit Papierspitzen der ISO-Größe 15 mikrobiologische Proben entnommen. Die Auswertung der Koloniebildenden Einheiten auf unspezifischen Nährböden ergab keine Unterschiede zwischen Schallaktivierung und intermittierender Ultraschallspülung. Dieses Resultat deckt sich mit den Ergebnissen der vorliegenden Studie.

\subsubsection{Vergleich der beiden ultraschallaktivierten Spülmethoden}

Zwischen den beiden Techniken zur Ultraschallaktivierung mittels kontinuierlicher und intermittierender Ultraschallspülung konnte im vorliegenden Versuch kein signifikanter Unterschied bezüglich der antibakteriellen Wirksamkeit festgestellt werden. Die bislang einzige experimentelle Studie zu diesem Thema stammt von Layton et al. (2015) und untersucht die Biofilmentfernung mit kontinuierlicher und intermittierender Ultraschallaktivierung. Die Autoren scannten einen extrahierten Oberkiefer-Schneidezahn mittels Mikrocomputertomografie (Mikro-CT) und stellten anhand des Datensatzes durchsichtige Silikonformen des Wurzelkanals her, die halbiert und jeweils auf eine Glasplatte geklebt wurden (Soft-Lithografie). In den künstlichen Wurzelkanälen wurde ein 
$21 \mathrm{~d}$ alter E. faecalis-Biofilm etabliert. Als Spülflüssigkeit diente destilliertes Wasser, welches entweder mittels kontinuierlicher oder intermittierender Ultraschallspülung appliziert wurde. Gegenüber der Positivkontrolle wurde ausschließlich in der Gruppe „kontinuierliche Ultraschallspülung“ eine signifikante Reduktion des Biofilms festgestellt. Zwischen der kontinuierlichen und intermittierenden Ultraschallspülung bestanden hingegen keine signifikanten Unterschiede. Layton et al. (2015) untersuchten ausschließlich die mechanischen Eigenschaften der verschiedenen Spülmethoden, da kein $\mathrm{NaOCl}$ oder andere chemisch wirksamen Spülflüssigkeiten eingesetzt wurden. Zusätzlich analysierten die Autoren die hydrodynamischen Effekte der verschiedenen Aktivierungstechniken. Bei der kontinuierlichen Ultraschallspülung konnten größere Strömungsgeschwindigkeiten und Scherkräfte entlang der Wurzelkanalwand beobachtet werden als in der Gruppe der intermittierenden Ultraschallspülung. Eine Vergleichbarkeit mit der vorliegenden Studie ist aufgrund der eingesetzten Spülflüssigkeit (destilliertes Wasser) nur teilweise gegeben. Die antimikrobiellen Effekte von aktivierten Spülflüssigkeiten resultieren hauptsächlich aus dem Einsatz von $\mathrm{NaOCl}$ als Desinfektionsmittel und dessen Synergien mit der eingesetzten Applikationsart (Cameron 1987, 1988; Paragliola et al. 2010). Mit der konventionellen Handspülung appliziertes $\mathrm{NaOCl}$ erreicht häufig bereits eine signifikante Reduktion der Bakterienzahl, während eine zusätzliche mechanische Aktivierung keine gesteigerte Desinfektionswirkung zur Folge hat (Brito et al. 2009; Bhuva et al. 2010; GuerreiroTanomaru et al. 2015).

Bei der Interpretation der Ergebnisse der vorliegenden Studie ist zu beachten, dass sie als Invitro-Studie und innerhalb ihrer Methodik zahlreiche Limitationen aufweist. Für nachfolgende In-vitro-Studien zur antimikrobiellen Wirksamkeit der verschiedenen Spülsysteme sollte es das Ziel sein, die klinischen Bedingungen in der Mundhöhle genauer zu simulieren. Beispielweise könnte durch den Einsatz von Polyspezies-Biofilmen mit längeren Inkubationszeiten die klinische Relevanz dieser Studien erhöht werden. Darüber hinaus scheint es sinnvoll, die Wirksamkeit der verwendeten Systeme in klinischen Studien zu überprüfen. Obwohl es einige Studien gibt, die in vivo durchgeführt wurden (Carver et al. 2007; Paiva et al. 2013; Rico-Romano et al. 2016), beschränkten sich diese auf die Gewinnung mikrobieller Proben und deren Auswertung mit Kulturmethoden oder molekularbiologischen Methoden. Zum jetzigen Zeitpunkt existiert lediglich eine klinische Langzeitstudie, die die Auswirkungen einer mechanischen Aktivierung der Spülflüssigkeit auf die Erfolgsrate von Wurzelkanalbehandlungen untersuchte (Liang et al. 2013). Dabei konnten keine signifikanten Unterschiede zwischen Handspülung und intermittierender Ultraschallspülung bei der Heilung periapikaler Entzündungen festgestellt werden. 
Zusammenfassend kann festgestellt werden, dass im vorliegenden In-vitro-Versuch keine signifikanten Unterschiede hinsichtlich der antibakteriellen Wirksamkeit auf einen E. faecalisBiofilm zwischen den verschiedenen Spültechniken ermittelt wurde. Dieses Ergebnis deckt sich mit den Resultaten anderer Autoren (Brito et al. 2009; Bhuva et al. 2010; GuerreiroTanomaru et al. 2015). Einige Autoren hingegen stellten signifikante Unterschiede zwischen den Spülmethoden fest (Carver et al. 2007; Pasqualini et al. 2010; Ordinola-Zapata et al. 2014). Diese kontroversen Ergebnisse sind möglicherweise auf Unterschiede in der Beschaffenheit des Biofilms (Pasqualini et al. 2010), der eingesetzten Menge an $\mathrm{NaOCl}$ (Carver et al. 2007) oder auf das vollständige Fehlen von $\mathrm{NaOCl}$ (Layton et al. 2015) zurückzuführen. 


\section{$7 \quad$ Zusammenfassung}

Ziel der Studie: Untersuchung der antibakteriellen Wirksamkeit verschiedener Methoden der Schall- und Ultraschallaktivierung von $1 \% \mathrm{NaOCl}$ auf einen $72 \mathrm{~h}$ alten intrakanalären $\mathrm{E}$. faecalis-Biofilm.

Material und Methode: Siebzig extrahierte einwurzelige Zähne mit abgeschlossenem Wurzelwachstum wurden auf eine standardisierte Wurzellänge von $15 \mathrm{~mm}$ gekürzt. Es folgte die maschinelle Erweiterung der Wurzelkanäle mit dem FlexMaster Nickel-Titan-System bis zur Größe 40/.02 bei einer Arbeitslänge von $14 \mathrm{~mm}$. Die Wurzelkanäle wurden nach jedem Instrumentenwechsel mit $2 \mathrm{ml}$ \% $\mathrm{NaOCl}$ gespült und erhielten eine Abschlussspülung mit $5 \mathrm{ml} 19 \%$ EDTA und $5 \mathrm{ml} 1 \% \mathrm{NaOCl}$. Die Zahnwurzeln wurden in Prothesenkunststoff eingebettet und sämtliche Prüfkörper für $20 \mathrm{~min}$ bei $121{ }^{\circ} \mathrm{C}$ autoklaviert. Zehn Zähne wurden randomisiert ausgewählt und für die spätere Verwendung zur Kontrolle im Rasterelektronenmikroskop (REM) separat aufbewahrt. Die übrigen Prüfkörper wurden in sechs Gruppen eingeteilt ( $\mathrm{n}=10)$ : Negativkontrolle, Positivkontrolle, Handspülung, Schall, intermittierende Ultraschallspülung (US-IF), kontinuierliche Ultraschallspülung (US-CF). Die Wurzelkanäle der Positivkontrolle, der experimentellen Gruppen und der Zähne zum Nachweis der Biofilmbildung wurden mit einer E. faecalis-Suspension (Stamm ATCC 29212) beimpft und für $72 \mathrm{~h}$ bei $37^{\circ} \mathrm{C}$ aerob kultiviert. Die Prüfkörper wurden nach $24 \mathrm{~h}$ und $48 \mathrm{~h}$ mit frischer E. faecalis-Suspension nachgeimpft. Die Zähne zum Nachweis der Schmierschichtentfernung und zum Nachweis des Biofilms wurden längs gespalten und zur Betrachtung im REM vorbereitet. Die Prüfkörper der experimentellen Gruppen wurden mit Hilfe des jeweiligen Spülsystems in einem 3 min dauernden Spülprotokoll mit $1 \% \mathrm{NaOCl}$ als Spüllösung desinfiziert. Nach der Desinfektion wurde der Wurzelkanal mit einer Papierspitze getrocknet, und es wurden durch zirkumferentes Feilen mit drei HedströmFeilen aufsteigender ISO-Größe Dentinspäne entnommen. Die Dentinspäne wurden in $\mathrm{NaCl}$ gelöst und auf drei Agar-Platten pro Prüfkörper ausplattiert. Die Proben der Positivkontrolle wurden zuvor 1:200 verdünnt. Nach $24 \mathrm{~h}$ Inkubation bei $37{ }^{\circ} \mathrm{C}$ wurden Fotografien angefertigt und die Kolonienbildenden Einheiten (KBE) gezählt. Die statistische Auswertung erfolgte mit einer Varianzanalyse $(\mathrm{p}<0,05)$.

Ergebnisse: Gegenüber der Positivkontrolle (Spülung mit 0,9\% $\mathrm{NaCl}$ ) fand in allen experimentellen Gruppen eine signifikante Reduktion des E. faecalis-Biofilms statt ( $\mathrm{p}<$ 0,0001). Zwischen den experimentellen Gruppen bestanden keine signifikanten Unterschiede hinsichtlich der antimikrobiellen Effektivität ( $p>0,45)$. Bei der Betrachtung 
der Wurzelhälften im REM wurden eine vollständige Schmierschichtentfernung und eine homogene Biofilmbildung nachgewiesen.

Schlussfolgerungen: Die Schall- und Ultraschallaktivierung von $1 \% \mathrm{NaOCl}$ zeigte gegenüber der Handspülung keine verbesserte antimikrobielle Wirkung auf einen $72 \mathrm{~h}$ alten E. faecalisBiofilm. 


\section{$8 \quad$ Literaturverzeichnis}

Adcock JM, Sidow SJ, Looney SW, Liu Y, McNally K, Lindsey K, Tay FR (2011):

Histologic evaluation of canal and isthmus debridement efficacies of two different irrigant delivery techniques in a closed system. J Endod $\underline{37}, 544-548$

Ahmad M (1989): Effect of ultrasonic instrumentation on Bacteroides intermedius. Endod Dent Traumatol $\underline{5}, 83-86$

Ahmad M, Pitt Ford TR, Crum LA (1987): Ultrasonic debridement of root canals: acoustic streaming and its possible role. J Endod 13, 490-499

Ahmad M, Pitt Ford TR, Crum LA, Walton AJ (1988): Ultrasonic debridement of root canals: acoustic cavitation and its relevance. J Endod 14, 486-493

Aktener BO, Cengiz T, Pişkin B (1989): The penetration of smear material into dentinal tubules during instrumentation with surface-active reagents: a scanning electron microscopic study. J Endod 15, 588-590

Baker NE, Liewehr FR, Buxton TB, Joyce AP (2004): Antibacterial efficacy of calcium hydroxide, iodine potassium iodide, betadine, and betadine scrub with and without surfactant against E faecalis in vitro. Oral Surg Oral Med Oral Pathol Oral Radiol Endod $\underline{98}, 359-364$

Barnett F, Trope M, Khoja M, Tronstad L (1985): Bacteriologic status of the root canal after sonic, ultrasonic and hand instrumentation. Endod Dent Traumatol 1, 228-231 Baumgartner JC, Ibay AC (1987): The chemical reactions of irrigants used for root canal debridement. J Endod 13, 47-51

Bhuva B, Patel S, Wilson R, Niazi S, Beighton D, Mannocci F (2010): The effectiveness of passive ultrasonic irrigation on intraradicular Enterococcus faecalis biofilms in extracted single-rooted human teeth. Int Endod J $\underline{43}, 241-250$

Boutsioukis C, Verhaagen B, Versluis M, Kastrinakis E, Wesselink PR, van der Sluis LWM (2010): Evaluation of irrigant flow in the root canal using different needle types by an unsteady computational fluid dynamics model. J Endod 36, 875-879

Brännström M, Johnson G (1974): Effects of various conditioners and cleaning agents on prepared dentin surfaces: a scanning electron microscopic investigation. J Prosthet Dent 31, 422-430 
Brito PR, Souza LC, Machado de Oliveira JC, Alves FR, De-Deus G, Lopes HP, Siqueira JF (2009): Comparison of the effectiveness of three irrigation techniques in reducing intracanal Enterococcus faecalis populations: an in vitro study. J Endod 35, 1422-1427

Brunner E, Domhof S, Langer F: Nonparametric analysis of longitudinal data in factorial experiments. J. Wiley, New York 2002

Burleson A, Nusstein J, Reader A, Beck M (2007): The in vivo evaluation of hand/rotary/ultrasound instrumentation in necrotic, human mandibular molars. J Endod $\underline{33}, 782-787$

Calt S, Serper A (2002): Time-dependent effects of EDTA on dentin structures. J Endod $\underline{28}, 17-19$

Cameron JA (1987): The synergistic relationship between ultrasound and sodium hypochlorite: a scanning electron microscope evaluation. J Endod 13, 541-545 Cameron JA (1988): The effect of ultrasonic endodontics on the temperature of the root canal wall. J Endod 14, 554-559

Caron G, Nham K, Bronnec F, Machtou P (2010): Effectiveness of different final irrigant activation protocols on smear layer removal in curved canals. J Endod 36, 1361-1366 Carver K, Nusstein J, Reader A, Beck M (2007): In vivo antibacterial efficacy of ultrasound after hand and rotary instrumentation in human mandibular molars. J Endod $\underline{33}, 1038$ 1043

Cergneux M, Ciucchi B, Dietschi JM, Holz J (1987): The influence of the smear layer on the sealing ability of canal obturation. Int Endod J 20, 228-232

Cohenca N, Silva LB, Silva RB, Nelson-Filho P, Heilborn C, Watanabe E, Saraiva MC (2013): Microbiological evaluation of different irrigation protocols on root canal disinfection in teeth with apical periodontitis: an in vivo study. Braz Dent J 24, 467-473

Cook GS, Costerton JW, Lamont RJ (1998): Biofilm formation by Porphyromonas gingivalis and Streptococcus gordonii. J Periodont Res $\underline{33}$, 323-327

Costerton JW, Stewart PS, Greenberg EP (1999): Bacterial biofilms: a common cause of persistent infections. Science $\underline{284}, 1318-1322$

Crumpton B, Goodell G, McClanahan S (2005): Effects on smear layer and debris removal with varying volumes of 17\% EDTA after rotary instrumentation. J Endod 31, 536-538 
Cunningham WT, Balekjian AY (1980): Effect of temperature on collagen-dissolving ability of sodium hypochlorite endodontic irrigant. Oral Surg Oral Med Oral Pathol 49, 175-177

Curtis TO, Sedgley CM (2012): Comparison of a continuous ultrasonic irrigation device and conventional needle irrigation in the removal of root canal debris. J Endod $\underline{38}, 1261-$ 1264

Davies DG (1998): The involvement of cell-to-cell signals in the development of a bacterial biofilm. Science $\underline{280}, 295-298$

de Gregorio C, Estevez R, Cisneros R, Heilborn C, Cohenca N (2009): Effect of EDTA, sonic, and ultrasonic activation on the penetration of sodium hypochlorite into simulated lateral canals: an in vitro study. J Endod $\underline{35}, 891-895$

de Paz LC (2007): Redefining the persistent infection in root canals: possible role of biofilm communities. J Endod $\underline{33}$, 652-662

Distel J, Hatton JF, Gillespie M (2002): Biofilm formation in medicated root canals. J Endod 28, 689-693

Donlan RM, Costerton JW (2002): Biofilms: survival mechanisms of clinically relevant microorganisms. Clin Microbiol Rev 15, 167-193

Du T, Wang Z, Shen Y, Ma J, Cao Y, Haapasalo M (2014): Effect of long-term exposure to endodontic disinfecting solutions on young and old Enterococcus faecalis biofilms in dentin canals. J Endod 40, 509-514

Edmond MB, Ober JF, Dawson JD, Weinbaum DL, Wenzel RP (1996): Vancomycinresistant enterococcal bacteremia: natural history and attributable mortality. Clin Infect Dis $\underline{23}, 1234-1239$

Evans M, Davies JK, Sundqvist G, Figdor D (2002): Mechanisms involved in the resistance of Enterococcus faecalis to calcium hydroxide. Int Endod J 35, 221-228

Fabricius L, Dahlén G, Sundqvist G, Happonen R, Möller AJ (2006): Influence of residual bacteria on periapical tissue healing after chemomechanical treatment and root filling of experimentally infected monkey teeth. Eur J Oral Sci 114, 278-285

Figdor D, Davies JK, Sundqvist G (2003): Starvation survival, growth and recovery of Enterococcus faecalis in human serum. Oral Microbiol Immunol 18, 234-239

Gilmore MS: The enterococci: pathogenesis, molecular biology, and antibiotic resistance. ASM Press, Washington, D.C. 2002 
Goldman LB, Goldman M, Kronman JH, Lin PS (1981): The efficacy of several irrigating solutions for endodontics: a scanning electron microscopic study. Oral Surg Oral Med Oral Pathol $\underline{52}, 197-204$

Gomes BP, Ferraz CC, Vienna ME, Berber VB, Teixeira FB, Souza-Filho FJ (2000): In vitro antimicrobial activity of several concentrations of sodium hypochlorite and chlorhexidine gluconate in the elimination of Enterococcus faecalis. Int Endod J 34, 424 428

Gründling GL, Zechin JG, Jardim WM, de Oliveira SD, de Figueiredo JAP (2011): Effect of ultrasonics on Enterococcus faecalis biofilm in a bovine tooth model. J Endod $\underline{37}$, $1128-1133$

Guerreiro-Tanomaru JM, Chávez-Andrade GM, de Faria-Júnior NB, Watanabe E, Tanomaru-Filho M (2015): Effect of passive ultrasonic irrigation on Enterococcus faecalis from root canals: an ex vivo study. Braz Dent J 26, 342-346

Gulabivala K, Stock CJ, Lewsey JD, Ghori S, Ng Y, Spratt DA (2004): Effectiveness of electrochemically activated water as an irrigant in an infected tooth model. Int Endod J $\underline{37}$, 624-631

Gulabivala K, Ng Y, Gilbertson M, Eames I (2010): The fluid mechanics of root canal irrigation. Physiol Meas $\underline{31}, \mathrm{R} 49-84$

Gulsahi K, Tirali RE, Cehreli SB, Karahan ZC, Uzunoglu E, Sabuncuoglu B (2014): The effect of temperature and contact time of sodium hypochlorite on human roots infected with Enterococcus faecalis and Candida albicans. Odontology 102, 36-41

Gupta J, Nikhil V, Jha P (2014): Corelation between machines assisted endodontic irrigant agitation and apical extrusion of debris and irrigant: a laboratory study. Scientific World J $\underline{2014}, 1-6$

Gutarts R, Nusstein J, Reader A, Beck M (2005): In vivo debridement efficacy of ultrasonic irrigation following hand-rotary instrumentation in human mandibular molars. J Endod $\underline{31}$, 166-170

Haapasalo M, Ørstavik D (1987): In vitro infection and of dentinal tubules. J Dent Res $\underline{66}$, 1375-1379

Haapasalo M, Shen Y, Qian W, Gao Y (2010): Irrigation in endodontics. Dent Clin North Am 느, 291-312 
Hall-Stoodley L, Costerton JW, Stoodley P (2004): Bacterial biofilms: from the natural environment to infectious diseases. Nat Rev Micro 2, 95-108

Hancock HH, Sigurdsson A, Trope M, Moiseiwitsch J (2001): Bacteria isolated after unsuccessful endodontic treatment in a north american population. Oral Surg Oral Med Oral Pathol Oral Radiol Endod 91, 579-586

Harrison AJ, Chivatxaranukul P, Parashos P, Messer HH (2010): The effect of ultrasonically activated irrigation on reduction of Enterococcus faecalis in experimentally infected root canals. Int Endod J $\underline{43}, 968-977$

Harrison JW, Hand RE (1981): The effect of dilution and organic matter on the antibacterial property of 5.25\% sodium hypochlorite. J Endod 7, 128-132

Herrera DR, Santos ZT, Tay LY, Silva EJ, Loguercio AD, Gomes BP (2013): Efficacy of different final irrigant activation protocols on smear layer removal by EDTA and citric acid. Microsc Res Tech $\underline{76}, 364-369$

Hockett JL, Dommisch JK, Johnson JD, Cohenca N (2008): Antimicrobial efficacy of two irrigation techniques in tapered and nontapered canal preparations: an in vitro study. $\mathrm{J}$ Endod 34, 1374-1377

Hübscher W, Barbakow F, Peters OA (2003): Root-canal preparation with FlexMaster: canal shapes analysed by micro-computed tomography. Int Endod J $\underline{36}, 740-747$

Hülsmann M, Heckendorff M, Lennon Á (2003): Chelating agents in root canal treatment: mode of action and indications for their use. Int Endod J $\underline{36}, 810-830$

Jett BD, Huycke M, Gilmore MS (1994): Virulence of enterococci. Clin Microbiol Rev $\underline{7}$, $462-478$

Jiang L, Verhaagen B, Versluis M, van der Sluis LWM (2010): Evaluation of a sonic device designed to activate irrigant in the root canal. J Endod 36, 143-146

Jiang L, Lak B, Eijsvogels LM, Wesselink PR, van der Sluis LWM (2012): Comparison of the cleaning efficacy of different final irrigation techniques. J Endod $\underline{38}, 838-841$

Joy J, Mathias J, Sagir VM, Babu BP, Chirayath KJ, Hameed H (2015): Bacterial biofilm removal using static and passive ultrasonic irrigation. J Int Oral Health $\underline{7}, 42-47$

Kakehashi S, Stanley HR, Fitzgerald RJ (1965): The effects of surgical exposures of dental pulps in germ-free and conventional laboratory rats. Oral Surg Oral Med Oral Pathol $\underline{20}$, 340-349 
Kishen A, Haapasalo M (2012): Biofilm models and methods of biofilm assessment. Endod Topics 22, 58-78

Klyn SL, Kirkpatrick TC, Rutledge RE (2010): In vitro comparisons of debris removal of the EndoActivator system, the F File, ultrasonic irrigation, and $\mathrm{NaOCl}$ irrigation alone after hand-rotary instrumentation in human mandibular molars. J Endod 36, 1367-1371

Kuah H, Lui J, Tseng PS, Chen N (2009): The effect of EDTA with and without ultrasonics on removal of the smear layer. J Endod $\underline{35}$, 393-396

Küçükkaya S (2014): Cytotoxic effect of endodontic irrigants in vitro. Med Sci Monit Basic Res $\underline{20}, 22-26$

Kumar V, Bahuguna N, Manan R (2015): Comparison of efficacy of various root canal irrigation systems in removal of smear layer generated at apical third: an SEM study. J Conserv Dent $\underline{18}, 252$

Layton G, Wu W, Selvaganapathy PR, Friedman S, Kishen A (2015): Fluid dynamics and biofilm removal generated by syringe-delivered and 2 ultrasonic-assisted irrigation methods: a novel experimental approach. J Endod 41, 884-889

Leighton TG: The acoustic bubble. Academic Press, London 1994

Li D, Jiang S, Yin X, Chang JWW, Ke J, Zhang C (2015): Efficacy of needle, ultrasonic, and EndoActivator irrigation and photon-induced photoacoustic streaming in removing calcium hydroxide from the main canal and isthmus: an in vitro micro-computed tomography and scanning electron microscopy study. Photomed Laser Surg $\underline{33}$, 330-337 Liang Y, Jiang LM, Jiang L, Chen X, Liu Y, Tian F, Bao X, Gao X, Versluis M, Wu M et al. (2013): Radiographic healing after a root canal treatment performed in single-rooted teeth with and without ultrasonic activation of the irrigant: a randomized controlled trial. J Endod 39, 1218-1225

Love RM, Jenkinson HF (2002): Invasion of dentinal tubules by oral bacteria. Crit Rev Oral Biol Med 13, 171-183

Lumley PJ, Walmsley AD, Walton RE, Rippin JW (1993): Cleaning of oval canals using ultrasonic or sonic instrumentation. J Endod 19, 453-457

Ma J, Wang Z, Shen Y, Haapasalo M (2011): A new noninvasive model to study the effectiveness of dentin disinfection by using confocal laser scanning microscopy. J Endod 37, 1380-1385 
Mac Collum WG, Hastings TW (1899): A case of acute endocarditis caused by Micrococcus zymogenes (nov. spec.), with a description of the microorganism. J Exp Med $\underline{4}, 521-534$

Macedo RG, Verhaagen B, Rivas DF, Gardeniers JGE, van der Sluis LWM, Wesselink PR, Versluis M (2014): Sonochemical and high-speed optical characterization of cavitation generated by an ultrasonically oscillating dental file in root canal models. Ultrason Sonochem 21, 324-335

Mader CL, Baumgartner JC, Peters DD (1984): Scanning electron microscopic investigation of the smeared layer on root canal walls. J Endod 10, 477-483

Mancini M, Cerroni L, Iorio L, Armellin E, Conte G, Cianconi L (2013): Smear layer removal and canal cleanliness using different irrigation systems (EndoActivator, EndoVac, and passive ultrasonic irrigation): field emission scanning electron microscopic evaluation in an in vitro study. J Endod $\underline{39}$, 1456-1460

Martin H, Cunningham W (1984): Endosonic endodontics: the ultrasonic synergistic system. Int Dent J 34, 198-203

Martin H, Cunningham WT, Norris JP (1980): A quantitative comparison of the ability of diamond and K-type files to remove dentin. Oral Surg Oral Med Oral Pathol 50, 566-568 Mayer BE, Peters OA, Barbakow F (2002): Effects of rotary instruments and ultrasonic irrigation on debris and smear layer scores: a scanning electron microscopic study. Int Endod J 35, 582-589

McComb D, Smith DC (1975): A preliminary scanning electron microscopic study of root canals after endodontic procedures. J Endod 1, 238-242

McNeill K, Hamilton IR (2003): Acid tolerance response of biofilm cells of Streptococcus mutans. FEMS Microbiol Lett 221, 25-30

Molander A, Reit C, Dahlén G, Kvist T (1998): Microbiological status of rootfilled teeth with apical periodontitis. Int Endod J $\underline{31}, 1-7$

Molven O, Olsen I, Kerekes K (1991): Scanning electron microscopy of bacteria in the apical part of root canals in permanent teeth with periapical lesions. Endod Dent Traumatol ㄱ, 226-229

Moorer WR, Wesselink PR (1982): Factors promoting the tissue dissolving capability of sodium hypochlorite. Int Endod J 15, 187-196

Nygaard-Østby B (1957): Chelation in root canal therapy. Odontol Tidskr 65, 3-11 
Ordinola-Zapata R, Bramante CM, Aprecio RM, Handysides R, Jaramillo DE (2014):

Biofilm removal by $6 \%$ sodium hypochlorite activated by different irrigation techniques.

Int Endod J 47, 659-666

Paiva SS, Siqueira JF, Rôças IN, Carmo FL, Leite DC, Ferreira DC, Rachid CT, Rosado AS

(2013): Molecular microbiological evaluation of passive ultrasonic activation as a

supplementary disinfecting step: a clinical study. J Endod 39, 190-194

Paragliola R, Franco V, Fabiani C, Mazzoni A, Nato F, Tay FR, Breschi L, Grandini S

(2010): Final rinse optimization: influence of different agitation protocols. J Endod $\underline{36}$, 282-285

Pashley DH (1992): Smear layer: overview of structure and function. Proc Finn Dent Soc $\underline{88}, 215-224$

Pasqualini D, Cuffini AM, Scotti N, Mandras N, Scalas D, Pera F, Berutti E (2010): Comparative evaluation of the antimicrobial efficacy of a 5\% sodium hypochlorite subsonic-activated solution. J Endod $\underline{36}, 1358-1360$

Pérez-Heredia M, Ferrer-Luque CM, González-Rodríguez MP, Martín-Peinado FJ, González-López S (2008): Decalcifying effect of 15\% EDTA, 15\% citric acid, 5\% phosphoric acid and 2.5\% sodium hypochlorite on root canal dentine. Int Endod J 41 , $418-423$

Peters CI, Koka RS, Highsmith S, Peters OA (2005): Calcium hydroxide dressings using different preparation and application modes: density and dissolution by simulated tissue pressure. Int Endod J 38, 889-895

Peters OA (2004): Current challenges and concepts in the preparation of root canal systems: a review. J Endod 30, 559-567

Radcliffe CE, Potouridou L, Qureshi R, Habahbeh N, Qualtrough A, Worthington H, Drucker DB (2004): Antimicrobial activity of varying concentrations of sodium hypochlorite on the endodontic microorganisms Actinomyces israelii, A. naeslundii, Candida albicans and Enterococcus faecalis. Int Endod J 37, 438-446

Ramsey M, Hartke A, Huycke M: The physiology and metabolism of enterococci. Creative Commons, Boston 2014

Retamozo B, Shabahang S, Johnson N, Aprecio RM, Torabinejad M (2010): Minimum contact time and concentration of sodium hypochlorite required to eliminate Enterococcus faecalis. J Endod 36, 520-523 
Rico-Romano C, Zubizarreta-Macho A, Baquero-Artigao M, Mena-Alvarez J (2016): An analysis in vivo of intracanal bacterial load before and after chemo-mechanical preparation: a comparative analysis of two irrigants and two activation techniques. J Clin Exp Dent $\underline{8}$, $9-13$

Rôças IN, Siqueira JF, Aboim MCR, Rosado AS (2004a): Denaturing gradient gel electrophoresis analysis of bacterial communities associated with failed endodontic treatment. Oral Surg Oral Med Oral Pathol Oral Radiol Endod 98, 741-749

Rôças IN, Siqueira JF, Santos K (2004b): Association of Enterococcus faecalis with different forms of periradicular diseases. J Endod $\underline{30}$, 315-320

Rödig T, Hülsmann M, Mühge M, Schäfers F (2002): Quality of preparation of oval distal root canals in mandibular molars using nickel-titanium instruments. Int Endod J $\underline{35}$, 919928

Rödig T, Bozkurt M, Konietschke F, Hülsmann M (2010): Comparison of the Vibringe system with syringe and passive ultrasonic irrigation in removing debris from simulated root canal irregularities. J Endod 36, 1410-1413

Rossi-Fedele G, Doğramaci EJ, Guastalli AR, Steier L, de Figueiredo JAP (2012):

Antagonistic interactions between sodium hypochlorite, chlorhexidine, EDTA, and citric acid. J Endod 38, 426-431

Roy RA, Ahmad M, Crum LA (1994): Physical mechanisms governing the hydrodynamic response of an oscillating ultrasonic file. Int Endod J 27, 197-207

Rubin LM, Skobe Z, Krakow AA, Gron P (1979): The effect of instrumentation and flushing of freshly extracted teeth in endodontic therapy: a scanning electron microscope study. J Endod $\underline{5}, 328-335$

Sassone LM, Fidel R, Faveri M, Fidel S, Figueiredo L, Feres M (2008): Microbiological evaluation of primary endodontic infections in teeth with and without sinus tract. Int Endod J 41, 508-515

Scelza MF, Teixeira AM, Scelza P (2003): Decalcifying effect of EDTA-T, 10\% citric acid, and 17\% EDTA on root canal dentin. Oral Surg Oral Med Oral Pathol Oral Radiol Endod $\underline{95}, 234-236$

Schilder H (1974): Cleaning and shaping the root canal. Dent Clin North Am 18, 269-296 
Schleifer KH, Kilpper-Balz R (1984): Transfer of Streptococcus faecalis and Streptococcus faecium to the genus Enterococcus nom. rev. as Enterococcus faecalis comb. nov. and Enterococcus faecium comb. nov. Int J Syst Bacteriol $\underline{34}, 31-34$

Sedgley CM, Nagel AC, Hall D, Applegate B (2005): Influence of irrigant needle depth in removing bioluminescent bacteria inoculated into instrumented root canals using real-time imaging in vitro. Int Endod J $\underline{38}, 97-104$

Seth AK, Geringer MR, Hong SJ, Leung KP, Galiano RD, Mustoe TA (2012):

Comparative analysis of single-species and polybacterial wound biofilms using a quantitative, in vivo, rabbit ear model. PLOS ONE $\underline{7, \text { e42897 }}$

Shen Y, Stojicic S, Haapasalo M (2010a): Bacterial viability in starved and revitalized biofilms: comparison of viability staining and direct culture. J Endod $\underline{36}, 1820-1823$

Shen Y, Stojicic S, Qian W, Olsen I, Haapasalo M (2010b): The synergistic antimicrobial effect by mechanical agitation and two chlorhexidine preparations on biofilm bacteria. J Endod 36, 100-104

Siqueira JF, Rôças IN (2004): Polymerase chain reaction-based analysis of microorganisms associated with failed endodontic treatment. Oral Surg Oral Med Oral Pathol Oral Radiol Endod 97, 85-94

Siqueira JF, Rôças IN, Favieri A, Lima K (2000): Chemomechanical reduction of the bacterial population in the root canal after instrumentation and irrigation with $1 \%, 2.5 \%$, and 5.25\% sodium hypochlorite. J Endod 26, 331-334

Sirén EK, Waltimo T'T, Ørstavik D, Haapasalo M (2000): Inactivation of local root canal medicaments by dentine: an in vitro study. Int Endod J 33, 126-131

Smith K, Hunter IS (2008): Efficacy of common hospital biocides with biofilms of multidrug resistant clinical isolates. J Med Microbiol 57, 966-973

Soukos NS, Chen PS, Morris JT, Ruggiero K, Abernethy AD, Som S, Foschi F, Doucette S, Luschke Bammann L, Fontana CR et al. (2006): Photodynamic therapy for endodontic disinfection. J Endod 32, 979-984

Spångberg L, Engström B, Langeland K (1973): Biologic effects of dental materials. 3. toxicity and antimicrobial effect of endodontic antiseptics in vitro. Oral Surg Oral Med Oral Pathol 36, 856-871 
Sundqvist G, Figdor D, Persson S, Sjögren U (1998): Microbiologic analysis of teeth with failed endodontic treatment and the outcome of conservative re-treatment. Oral Surg Oral

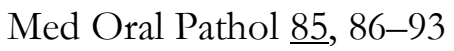

Sutton NA, Hughes N, Handley PS (1994): A comparison of conventional SEM techniques, low temperature SEM and the electroscan wet scanning electron microscope to study the structure of a biofilm of Streptococcus crista CR3. J Appl Microbiol 76, 448-454

Tendolkar PM, Baghdayan AS, Shankar N (2003): Pathogenic enterococci: new developments in the 21st century. Cell Mol Life Sci 60, 2622-2636

Townsend C, Maki J (2009): An in vitro comparison of new irrigation and agitation techniques to ultrasonic agitation in removing bacteria from a simulated root canal. J Endod $\underline{35}, 1040-1043$

Tronstad L, Barnett F, Cervone F (1990): Periapical bacterial plaque in teeth refractory to endodontic treatment. Endod Dent Traumatol $\underline{6}, 73-77$ van der Sluis LW, Wu MK, Wesselink PR (2005): A comparison between a smooth wire and a K-file in removing artificially placed dentine debris from root canals in resin blocks during ultrasonic irrigation. Int Dent J $\underline{38}, 593-596$

van der Sluis LW, Versluis M, Wu MK, Wesselink PR (2007): Passive ultrasonic irrigation of the root canal: a review of the literature. Int Endod J 40, 415-426

Vertucci FJ (2005): Root canal morphology and its relationship to endodontic procedures. Endod Topics 10, 3-29

Wang Z, Shen Y, Haapasalo M (2012): Effectiveness of endodontic disinfecting solutions against young and old Enterococcus faecalis biofilms in dentin canals. J Endod 38, 13761379

Wayman BE, Kopp WM, Pinero GJ, Lazzari EP (1979): Citric and lactic acids as root canal irrigants in vitro. J Endod 5, 258-265

White RR, Goldman M, Lin PS (1987): The influence of the smeared layer upon dentinal tubule penetration by endodontic filling materials. Part II. J Endod 13, 369-374

Wu MK, van der Sluis LW, Wesselink PR (2003): The capability of two hand instrumentation techniques to remove the inner layer of dentine in oval canals. Int Endod J $\underline{36}, 218-224$

Wu MK, Wesselink PR (2001): A primary observation on the preparation and obturation of oval canals. Int Endod J 34, 137-141 
Yang S, Bae K (2002): Scanning electron microscopy study of the adhesion of Prevotella nigrescens to the dentin of prepared root canals. J Endod 28, 433-437

Zehnder M (2006): Root canal irrigants. J Endod 32, 389-398

Zehnder M, Guggenheim B (2009): The mysterious appearance of enterococci in filled root canals. Int Endod J 42, 277-287

Zehnder M, Schmidlin P, Sener B, Waltimo T (2005): Chelation in root canal therapy reconsidered. J Endod $\underline{31}, 817-820$ 


\section{Danksagung}

Frau Oberärztin PD Dr. med. dent. Tina Rödig aus der Poliklinik für Präventive Zahnmedizin, Parodontologie und Kariologie des Zentrum Zahn-Mund-Kieferheilkunde der Universität Göttingen möchte ich für die engagierte Betreuung während der Planung und Durchführung der Versuche sowie ihre konstruktive Kritik und Geduld bei der Erstellung und Korrektur meiner Dissertation danken.

Des Weiteren gilt mein Dank Frau Monika Hoch, ebenfalls aus der Poliklinik für Präventive Zahnmedizin, Parodontologie und Kariologie, für ihr Engagement und den lösungsorientierten Input während der Laborversuche.

Bei Herrn Hans-Georg Sydow aus der Anatomie der Universität Göttingen bedanke ich mich für die Hilfe bei der Vorbereitung der Proben und die Erstellung der rasterelektronenmikroskopischen Aufnahmen.

Herrn Prof. Dr. rer. nat. Frank Konietschke von der University of Texas in Dallas möchte ich für seine Hilfe bei der statistischen Auswertung der Versuchsergebnisse danken.

Zudem gilt mein Dank der gesamten Abteilung für Präventive Zahnmedizin, Parodontologie und Kariologie unter der Leitung von Frau Prof. Dr. med. dent. Annette Wiegand für die konstruktive und kollegiale Arbeitsumgebung, die die Erstellung meiner Dissertation erst ermöglicht hat. 